\title{
Factors Controlling Photochemical Cleavage of \\ the Energetically Unfavorable Ph-Se Bond of Alkyl Phenyl Selenides \\ - Supporting Information-
}

\author{
Akihiko Ouchi,* Suyou Liu, Zhong Li, S. Ajaya Kumar, Toshiaki Suzuki, Hyugano Takeshi, \\ and Haruo Kitahara \\ National Institute of Advanced Industrial Science and Technology (AIST), Tsukuba, Ibaraki \\ 305-8565, Japan, the University of Tsukuba, Ibaraki 305-8571, Japan, \\ and Faculty of Education, Hirosaki University, Hirosaki 036-8560, Japan
}

\section{Contents}

Page 2-5: Analytical and spectroscopic data of $\mathbf{1 a -} d_{11}, \mathbf{1 b}, \mathbf{1 d}, \mathbf{1 e}, \mathbf{5 d}, \mathbf{5 e}, \mathbf{8 e}$, and synthetic procedure of $5 \mathbf{e}$

Page 6: Figure S1. Low-pressure mercury lamp photolysis of 1a in $n$-hexane.

Page 7: Figure S2. KrF excimer laser photolysis of pentyl phenyl selenide (1a) in $n$-hexane.

Page 7: Figure S3. KrF excimer laser photolysis of dipentyl selenide (5a) and diphenyl diselenide (7) in $n$-hexane.

Page 8: Figure S4. XeCl excimer laser photolysis of pentyl phenyl selenide (1a) in $n$-hexane.

Page 9: Figure S5. ArF excimer laser photolysis of pentyl phenyl selenide (1a) in $n$-hexane.

Page 10: Figure S6. KrF excimer laser photolysis of pentyl phenyl selenide (1a) in $n$-heptane.

Page 10: Figure S7. KrF excimer laser photolysis of pentyl phenyl selenide (1a) in $n$-dodecane.

Page 11: Figure S8. KrF excimer laser photolysis of pentyl phenyl selenide (1a) in $n$-tetradecane.

Page 11: Figure S9. KrF excimer laser photolysis of pentyl phenyl selenide (1a) in $n$-hexadecane.

Page 12: Figure S10. KrF excimer laser photolysis of pentyl phenyl selenide (1a) in cyclopentane.

Page 12: Figure S11. KrF excimer laser photolysis of pentyl phenyl selenide (1a) in cyclohexane.

Page 13: Figure S12. KrF excimer laser photolysis of pentyl phenyl selenide (1a) in cycloheptane.

Page 13: Figure S13. KrF excimer laser photolysis of pentyl phenyl selenide (1a) in cyclooctane.

Page 14: Figure S14. KrF excimer laser photolysis of pentyl phenyl selenide (1a) in cyclodecane.

Page 14: Figure S15. KrF excimer laser photolysis of $n$-pentyl phenyl selenide (1a), 1-ethylpropyl phenyl selenide (1b), and tert-butyl phenyl selenide (1) in cyclohexane.

Page 15: Figure S16. KrF excimer laser photolysis of allyl phenyl selenide (1d) and

2-methylallyl phenyl selenides (1e) in cyclohexane.

Page 16-37: NMR spectra of $\mathbf{1 a - e , ~} \mathbf{1 a}-d_{11}, \mathbf{5 a}, \mathbf{b}, \mathbf{d}, \mathbf{e}$, and $\mathbf{8 e}$. 


\section{Analytical and spectroscopic data of $1 \mathrm{a}-d_{11}, 1 \mathrm{~b}, 1 \mathrm{~d}, 1 \mathrm{e}, 5 \mathrm{~b}, 5 \mathrm{~d}, 5 \mathrm{e}, 8 \mathrm{e}$, and synthetic}

\section{procedure of $5 \mathbf{b}$.}

NMR spectra were recorded with $\mathrm{CDCl}_{3}$ as solvent. As internal standards, TMS was used for ${ }^{1} \mathrm{H}$ NMR ( $\left.\delta: 0 \mathrm{ppm}\right)$ and $\mathrm{CDCl}_{3}$ for ${ }^{13} \mathrm{C}$ NMR NMR ( $\left.\delta: 77.0 \mathrm{ppm}\right)$ analyses.

\section{Analytical and spectroscopic data of $1 \mathrm{a}-d_{11}, 1 \mathrm{~b}, 1 \mathrm{~d}, 1 \mathrm{e}, 5 \mathrm{~d}, 5 \mathrm{e}$, and $8 \mathrm{e}$.}

Pentyl- $\boldsymbol{d}_{\mathbf{1 1}}$ phenyl selenide $\left(\mathbf{1} \mathbf{a}-d_{11}\right)$. Diphenyl diselenide: $0.60 \mathrm{~g}(1.92 \mathrm{mmol})$; EtOH : 50 $\mathrm{mL} ; \mathrm{NaBH}_{4}: 0.40 \mathrm{~g}(10.5 \mathrm{mmol}) ; 1$-bromopentane- $d_{11}: 0.50 \mathrm{~g}(3.10 \mathrm{mmol})$. Purified by silica gel column chromatography (hexane) instead of distillation. Yield: $0.72 \mathrm{~g}(98 \%)$, faintly yellow oil.

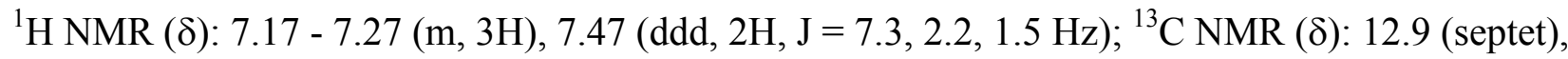
20.8 (quintet), 27.0 (quintet), 28.6 (quintet), 30.6 (quintet), 126.5, 128.9, 130.7, 132.2; IR (neat): 463, 531, 670, 691, 732, 919, 968, 998, 1023, 1057, 1075, 1085, 1177, 1299, 1237, 1379, 1437, $1580,1745,1794,1870,1943,2071,2102,2151,2213,2998,3016,3058,3072 \mathrm{~cm}^{-1}$; MS, m/e (relative intensity): 30 (17), 34 (22), 46 (28), 50 (100), 51 (21), 77 (20), 79 (29), 93 (11), 155 (15), $156(11), 157$ (35), $159(56), 161(10), 235\left(5, \mathrm{M}^{+}\right), 236\left(6, \mathrm{M}^{+}\right), 237\left(12, \mathrm{M}^{+}\right), 239\left(19, \mathrm{M}^{+}\right)$.

1-Ethylpropyl phenyl selenide (1b). ${ }^{1,2}$ Diphenyl diselenide: $3.41 \mathrm{~g}$ (10.9 mmol); EtOH : $30 \mathrm{~mL}$; $\mathrm{NaBH}_{4}: 0.83 \mathrm{~g}$ (21.9 mmol); 3-bromopentane: $3.00 \mathrm{~g}$ (19.9 mmol). Yield: $3.05 \mathrm{~g}(68 \%)$, b.p. $51.5-52.0^{\circ} \mathrm{C}\left(0.21\right.$ Torr), faintly yellow oil. ${ }^{1} \mathrm{H}$ NMR $(\delta): 1.01$ (t, 6H, J = 7.3 Hz), 1.67 (dq, $4 \mathrm{H}, \mathrm{J}=7.3,6.6 \mathrm{~Hz}$ ), 3.07 (quintet, $1 \mathrm{H}, \mathrm{J}=6.6 \mathrm{~Hz}), 7.2-7.3(\mathrm{~m}, 3 \mathrm{H}), 7.47-7.62(\mathrm{~m}, 2 \mathrm{H}) ;{ }^{13} \mathrm{C}$ NMR (ס): 12.4, 27.9, 50.6, 127.4, 129.1, 130.0, 135.0; IR (neat): 468, 472, 515, 671, 693, 739, $801,814,845,862,871,911,1000,1022,1064,1074,1119,1140,1190,1272,1300,1327,1338$, 1350, 1379, 1437, 1458, 1478, 1580, 1804, 1877, 1946, 2851, 2874, 2932, 2965, 3015, 3059, $3071 \mathrm{~cm}^{-1}$; MS, m/e (relative intensity): 27 (7), 29 (12), 39 (9), 41 (17), 43 (71), 51 (8), 55 (10), 71 (12), 77 (18), 78 (36), 154 (21), 155 (22), 156 (49), 157 (15), 158 (100), 159 (9), 160 (18), $226\left(13, \mathrm{M}^{+}\right), 228\left(26, \mathrm{M}^{+}\right)$. Elemental analysis. Calcd for $\mathrm{C}_{11} \mathrm{H}_{16} \mathrm{Se}(\%)$ : C, 58.15; H, 7.10. Found (\%): C, 57.78; H, 7.15. 
Allyl phenyl selenide (1d). ${ }^{1,3,4,6}$ Diphenyl diselenide: $5.15 \mathrm{~g}(16.5 \mathrm{mmol})$; EtOH : $50 \mathrm{~mL}$; $\mathrm{NaBH}_{4}$ : $1.25 \mathrm{~g}$ (33.1 mmol); allyl chloride: $2.30 \mathrm{~g}$ (30.1 mmol). Yield: $4.41 \mathrm{~g}$ (74 \%), b.p. 33 $34{ }^{\circ} \mathrm{C}(0.18$ Torr $)\left[\right.$ lit. $50{ }^{\circ} \mathrm{C}(0.5 \text { Torr })^{4}$; $65-68^{\circ} \mathrm{C}(1.0 \text { Torr })^{5}$ ], colorless oil. ${ }^{1} \mathrm{H}$ NMR $(\delta): 3.52$ $(\mathrm{d}, 2 \mathrm{H}, \mathrm{J}=7.4 \mathrm{~Hz}), 4.94(\mathrm{dd}, 1 \mathrm{H}, \mathrm{J}=1.3,9.8 \mathrm{~Hz}), 4.96(\mathrm{dd}, 1 \mathrm{H}, \mathrm{J}=1.3,16.9), 5.95(\mathrm{ddt}, 1 \mathrm{H}, \mathrm{J}=$

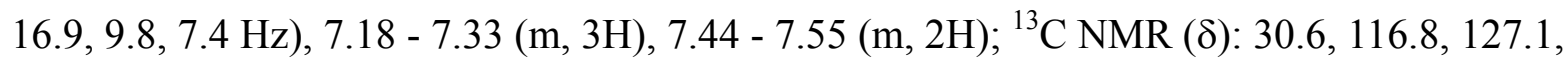
128.9, 129.8, 133.2, 134.3; IR (neat): 471, 540, 615, 672, 691, 737, 837, 914, 986, 1000, 1022, 1074, 1181, 1194, 1300, 1327, 1402, 1437, 1478, 1580, 1632, 1744, 1827, 1873, 1948, 2928, 2978, 3011, 3058, $3073 \mathrm{~cm}^{-1}$; MS, m/e (relative intensity): 39 (39), 41 (100), 50 (12), 51 (24), 65 (10), 77 (46), 78 (25), 91 (26), 104 (41), 115 (16), 116 (7), 117 (77), 118 (12), 153 (12), 154 (13), 155 (30), 156 (8), 157 (59), 158 (10), 159 (11), 183 (11), 194 (15, M+), 195 (15, M ), $196(38$, $\left.\mathrm{M}^{+}\right), 198\left(77, \mathrm{M}^{+}\right), 199(8), 200\left(14, \mathrm{M}^{+}\right)$. High resolution MS. Calcd for $\mathrm{C}_{9} \mathrm{H}_{10} \mathrm{Se}$ : 195.9954, 197.9947. Found: 195.9952, 197.9950.

2-Methylallyl phenyl selenide (1e). ${ }^{6,7}$ Diphenyl diselenide: $5.15 \mathrm{~g}(16.5 \mathrm{mmol})$; EtOH : $50 \mathrm{~mL} ; \mathrm{NaBH}_{4}: 1.25 \mathrm{~g}$ (33.1 mmol); 2-methylallyl chloride: $2.72 \mathrm{~g}(30.0 \mathrm{mmol})$. Yield: $5.49 \mathrm{~g}$ $(87 \%), 43.5-44.5{ }^{\circ} \mathrm{C}(0.22$ Torr $)\left[\right.$ lit. $^{7} 80{ }^{\circ} \mathrm{C}(0.5$ Torr $)$ ], faintly yellow oil. ${ }^{1} \mathrm{H} \mathrm{NMR}(\delta): 1.86$ (brs, 3H), $3.52(\mathrm{~d}, 2 \mathrm{H}, \mathrm{J}=0.77 \mathrm{~Hz}), 4.65$ - $4.75(\mathrm{~m}, 2 \mathrm{H}), 7.18$ - $7.33(\mathrm{~m}, 3 \mathrm{H}), 7.44$ - $7.56(\mathrm{~m}$, $2 \mathrm{H}) ;{ }^{13} \mathrm{C}$ NMR $(\delta): 21.3,36.0,113.4,127.0,128.8,130.4,133.4,141.7$; IR (neat): 452, 463, 470, $600,671,691,737,893,1001,1022,1068,1074,1132,1157,1186,1287,1300,1327,1373$, 1400, 1437, 1478, 1580, 1644, 1746, 1798, 1873, 1946, 2919, 2938, 2973, 3059, $3075 \mathrm{~cm}^{-1}$; MS, m/e (relative intensity): 27 (10), 29 (23), 39 (14), 51 (10), 53 (9), 55 (100), 77 (16), 78 (11), 91 (32), 117 (6), 118 (12), 131 (24), 155 (7), 157 (13), $208\left(6, \mathrm{M}^{+}\right), 209\left(6, \mathrm{M}^{+}\right), 210\left(16, \mathrm{M}^{+}\right), 212$ $\left(32, \mathrm{M}^{+}\right), 214\left(6, \mathrm{M}^{+}\right)$. Elemental analysis. Calcd for $\mathrm{C}_{10} \mathrm{H}_{12} \mathrm{Se}(\%)$ : C, 56.88; H, 5.73. Found (\%): C, 56.74; H, 5.65.

Diallyl selenide (5d). ${ }^{8}$ Allyl bromide: $5.16 \mathrm{~g}$ (42.7 mmol); $\mathrm{Na}_{2} \mathrm{Se}: 2.5 \mathrm{~g}$ (20 mmol); THF: $50 \mathrm{~mL}$. Yield: $2.42 \mathrm{~g}\left(75 \%\right.$ ), faintly yellow oil [lit. ${ }^{9} 50{ }^{\circ} \mathrm{C}\left(21\right.$ Torr) ${ }^{1}{ }^{1} \mathrm{H}$ NMR $(\delta): 3.53$ (d, 4H, J $=7.6 \mathrm{~Hz}), 5.02(\mathrm{~d}, 2 \mathrm{H}, \mathrm{J}=9.8 \mathrm{~Hz}), 5.03(\mathrm{~d}, 2 \mathrm{H}, \mathrm{J}=17.5 \mathrm{~Hz}), 5.88(\mathrm{ddt}, 2 \mathrm{H}, \mathrm{J}=7.6,9.8,17.5$ $\mathrm{Hz}) ;{ }^{13} \mathrm{C}$ NMR $(\delta): 25.4,116.4,135.0$; IR (neat): 538, 694, 802, 831, 862, 909, 987, 1056, 1175, 
$1198,1292,1399,1428,1631,1825,2358,2814,2850,2923,2976,3006,3035,3080 \mathrm{~cm}^{-1}$; MS, m/e (relative intensity): 38 (14), 39 (100), 40 (12), 41 (79), 81 (27), 91 (13), 93 (26), 116 (13), 118 (12), 119 (27), $121(51), 160\left(11, \mathrm{M}^{+}\right), 162\left(22, \mathrm{M}^{+}\right)$. High resolution MS. Calcd for $\mathrm{C}_{6} \mathrm{H}_{10} \mathrm{Se}: 159.9955,161.9947$. Found: 159.9958, 161.9904.

Bis(2-methylallyl) selenide (5e). 2-Methylallyl chloride: $3.8 \mathrm{~g}$ (42.0 mmol); $\mathrm{Na}_{2} \mathrm{Se}: 2.5 \mathrm{~g}$ (20 mmol); THF: $50 \mathrm{~mL}$. Yield: $2.03 \mathrm{~g}$ (54 \%), faintly yellow oil. ${ }^{1} \mathrm{H}$ NMR $(\delta): 1.85$ (s, 6H), 3.14 (s, 4H), 4.812 (s, 2H), 4.814 (s, 2H); ${ }^{13} \mathrm{C}$ NMR (ס): 21.3, 30.9, 112.9, 142.3; IR (neat): 474, 607, $728,810,828,887,1007,1035,1130,1181,1285,1372,1400,1423,1441,1642,1787,2725$, 2918, 2930, 2971, $3078 \mathrm{~cm}^{-1}$; MS, m/e (relative intensity): 38 (10), 39 (100), 40 (17), 41 (67), 51 (15), 53 (61), 55 (39), 56 (15), 65 (14), 67 (16), 77 (10), 79 (15), 91 (51), 92 (15), 93 (17), 95 (18), 105 (16), 107 (54), 109 (36), 131 (11), 133 (23), 135 (25), 173 (11), 186 (11, M ), 188 (20, $\left.\mathrm{M}^{+}\right), 190\left(10, \mathrm{M}^{+}\right)$. High resolution MS. Calcd for $\mathrm{C}_{8} \mathrm{H}_{14} \mathrm{Se}: 188.0268,190.0260$. Found: 188.0274, 190.0270 .

2-Methylallylcyclohexane (8e $)^{9,10}$ was prepared according to a reported procedure. ${ }^{9}$ Yield: $17 \%$, colorless oil, b.p. $57-58{ }^{\circ} \mathrm{C}\left(15\right.$ Torr) [lit. $\left.59-60{ }^{\circ} \mathrm{C}(15 \text { Torr })^{9} ; 172{ }^{\circ} \mathrm{C}(740 \text { Torr })^{9}\right] .{ }^{1} \mathrm{H}$ NMR ( $\delta): 0.84(\mathrm{~m}, 2 \mathrm{H}), 1.09-1.27$ (m, 3H), $1.32-1.47(\mathrm{~m}, 1 \mathrm{H}), 1.61-1.73(\mathrm{~m}, 8 \mathrm{H}), 1.89(\mathrm{~d}$, $2 \mathrm{H}, \mathrm{J}=7.0 \mathrm{~Hz}), 4.62(\mathrm{~s}, 1 \mathrm{H}), 4.71(\mathrm{~s}, 1 \mathrm{H}) ;{ }^{13} \mathrm{C} \mathrm{NMR}(\delta): 22.33,26.36,26.63,33.26,35.38,46.18$, $111.02,144.59$.

\section{Synthetic procedure of $5 b$.}

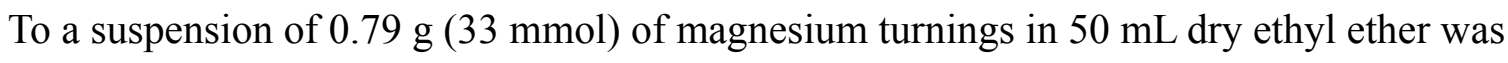


temperature. After completion of the addition, the reaction mixture was stirred at room temperature for $2 \mathrm{~h}$ under a nitrogen atmosphere and then $2.6 \mathrm{~g}(32.9 \mathrm{mmol})$ of selenium powder was gradually added to the solution in $1 \mathrm{~h}$. An aqueous solution of $\mathrm{NH}_{4} \mathrm{Cl}$ was added to the reaction mixture at room temperature and the organic layer was separated. The aqueous solution was extracted with ethyl ether and combined organic layes was washed successively with 
$\mathrm{NaHCO}_{3}$ and brine, and then dried over anhydrous $\mathrm{Na}_{2} \mathrm{SO}_{4}$. The solvent was removed in vacuo to give $3.0 \mathrm{~g}$ of crude bis(1-ethylpropyl) diselenide as a yellow powder. The crude bis(1-ethylpropyl) diselenide was suspended in $50 \mathrm{~mL}$ of EtOH and $1.5 \mathrm{~g}(39.7 \mathrm{~mol}) \mathrm{of}^{\mathrm{NaBH}_{4}}$ was added to the reaction mixture in portions. When the reaction mixture became colorless solution, $3.2 \mathrm{~g}(21 \mathrm{mmol})$ of 3-bromopentane was added to the solution and stirred overnight at room temperature. The reaction mixture was then poured into water, extracted with hexane, and the organic layer was washed successively with aqueous $\mathrm{Na}_{2} \mathrm{CO}_{3}$ and brine, and dried over anhydrous $\mathrm{MgSO}_{4}$. The solvent was then removed in vacuo and crude product was purified by silica gel column chromatography (hexane) to give $2.8 \mathrm{~g}$ (yield: $60 \%$ of pure $\mathbf{5 b}$ as a colourless oil. ${ }^{1} \mathrm{H}$ NMR (ס): 0.99 (t, 12H, J = $7.3 \mathrm{~Hz}$ ), 1.66 (ddq, 4H, J = 6.4, 7.3, $21 \mathrm{~Hz}$ ), 1.69 (ddq, 4H, J = 6.4, 7.3, $21 \mathrm{~Hz}$ ), 2.69 (quintet, $2 \mathrm{H}, \mathrm{J}=6.4 \mathrm{~Hz}$ ); ${ }^{13} \mathrm{C} \mathrm{NMR}(\delta): 12.2,28.6,45.1$; IR (neat): 611, $780,800,814,845,861,904,1010,1034,1050,1118,1140,1185,1272,1281,1295,1326,1338$,

$1350,1378,1454,1459,2583,2667,2729,2851,2873,2930,2963,3158 \mathrm{~cm}^{-1}$; MS, m/e (relative intensity): 39 (19), 41 (64), 42 (16), 43 (100), 55 (14), 69 (23), 70 (20), 71 (54), 150 (11), 151 (14), $152(18), 220\left(7, \mathrm{M}^{+}\right), 222\left(12, \mathrm{M}^{+}\right)$. High resolution MS. Calcd for $\mathrm{C}_{10} \mathrm{H}_{14} \mathrm{Se}: 220.0893$, 222.0886. Found: 220.0907, 222.0930.

\section{References}

1. Duddeck, H. ; Wagner, P. ; Rys, B. Magn. Reson. Chem., 1993, 31, 736-742.

2. Sakakibara, M.; Katsumata, K.; Watanabe, Y.; Toru, T.; Ueno, Y. Synthesis, 1992, 377-379.

3. Ranu, B. C.; Mandal, T.; Samanta, S. Org. Lett., 2003, 5, 1439-1441.

4. Barton, D. H. R.; Crich, D. J. Chem. Soc. Perkin Trans. 1, 1986, 1613-1620.

5. Binns, M. R.; Haynes, R. K. J. Org. Chem., 1981, 46, 3790-3795.

6. Lebarillier, L.; Outurquin, F.; Paulmier, C. Tetrahedron, 2000, 56, 7483-7494.

7. Reich, H. J.; Wollowitz, S. ; Trend, J. E.; Chow, F.; Wendelborn, D. F. J. Org. Chem., 1978, 43, 1697-1705.

8. Ryan, M. D.; Harpp, D. N. Tetrahedron Lett., 1992, 33, $2129-2132$.

9. Farkaš, J.; Novák, J. J. K. Collect. Czech. Chem. Commun., 1960, 25, 1815-1823.

10. Uijttewaal, A. P.; Jonkers, F. L.; van der Gen, A. J. Org. Chem., 1979, 44, 3157-3168. 


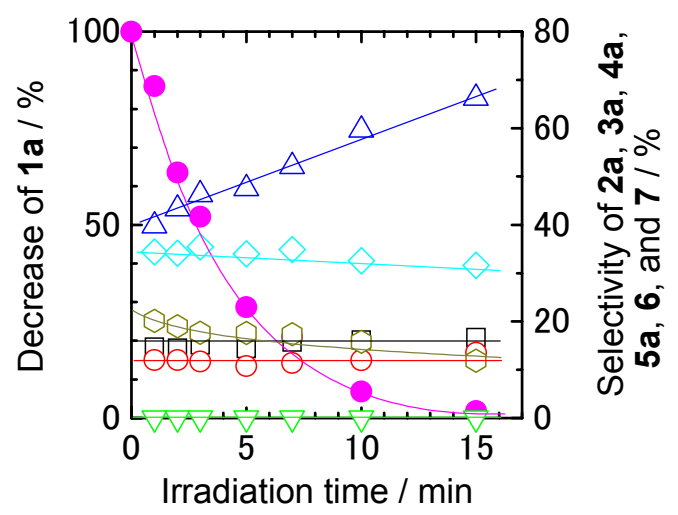

Figure S1. Low-pressure mercury lamp photolysis of $\mathbf{1 a}$ in $n$-hexane. Decrease in 1a $(\bullet)$ and selectivity of 1-pentene (2a, $\square), n$-pentane (3a, $\bigcirc), n$-decane $(\mathbf{4 a}, \nabla)$, dipentyl selenide (5a, $\diamond)$, benzene $(6, \triangle)$, and diphenyl diselenide $(7, \oslash)$ as a function of the irradiation time. Concentration: $10^{-3} \mathrm{M}$ in $n$-hexane, optical path: $1 \mathrm{~mm}$, intensity of the low-pressure mercury lamp: $214 \mu \mathrm{W} \mathrm{cm}{ }^{-2}$, room temperature. Results are the average of at least two independent runs.

\section{Experimental.}

Photolysis of 1 a was conducted on $50 \mu \mathrm{L}$ of $10^{-3} \mathrm{~mol} \mathrm{dm}^{-3}(=\mathrm{M})$ n-hexane solutions under a nitrogen atmosphere at room temperature using a synthetic quartz cell of $10-\mathrm{mm}$ in width and 1-mm optical path. The solutions were degassed with three freeze-pump-thaw cycles before photolysis. The photolyses were conducted with a $6 \mathrm{~W}$ low-pressure $\mathrm{Hg}$ lamp (Ushio ULO-6AB-5A) fitted with a Toshiba UV-25 filter $\left(214 \mu \mathrm{W} \cdot \mathrm{cm}^{-2}\right)$. Light intensity of the low-pressure mercury lamp was measured using a Ushio USR-40D spectroradiometer in the range of $200-800 \mathrm{~nm}$. The consumption of 1a and the product yield were analyzed similar to the case in the laser photolysis. 




Number of laser shots

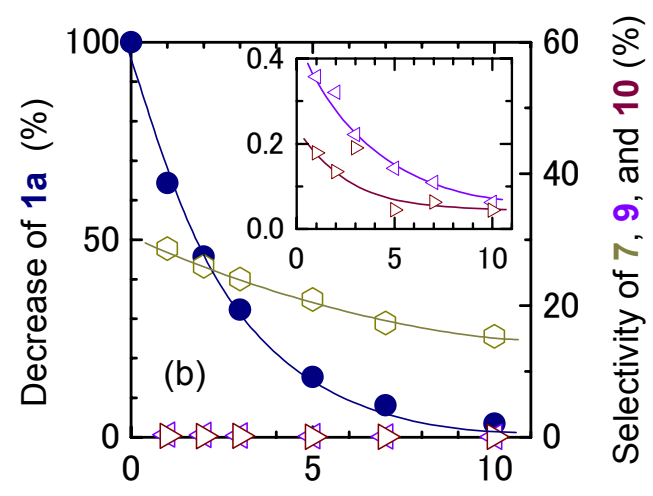

No of laser pulses

Figure S2. KrF excimer laser photolysis of pentyl phenyl selenide (1a) in $n$-hexane. (a) Decrease in $1 \mathrm{a}(\bigcirc)$ and selectivity of 1 -hexene $(\checkmark)$, pentylbenzene $(\triangle)$, and undecane $(\star)$ as a function of the number of laser shots (glc analyses). (b) Decrease in 1a (O), selectivity of diphenyl diselenide $(7, \bigcirc)$, 2-pentylphenyl phenyl selenide $(9, \triangleleft)$, and 4-pentylphenyl phenyl selenide $(10, \triangleright)$ as a function of the number of the laser shots (HPLC analyses). Laser: $\mathrm{KrF}$ excimer laser. Concentration: $10^{-3} \mathrm{M}$ in $n$-hexane, optical path: $1 \mathrm{~mm}$, laser fluence: $100 \mathrm{~mJ}$ $\mathrm{cm}^{-2}$ pulse ${ }^{-1}$, room temperature. Results are the average of at least two independent runs.

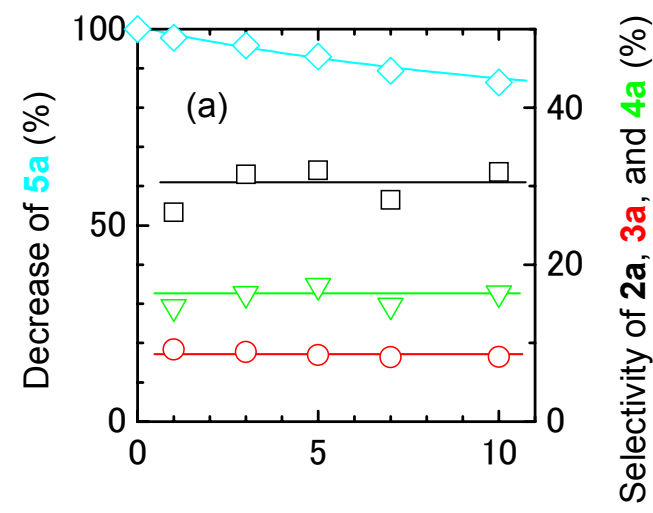

Number of laser shots

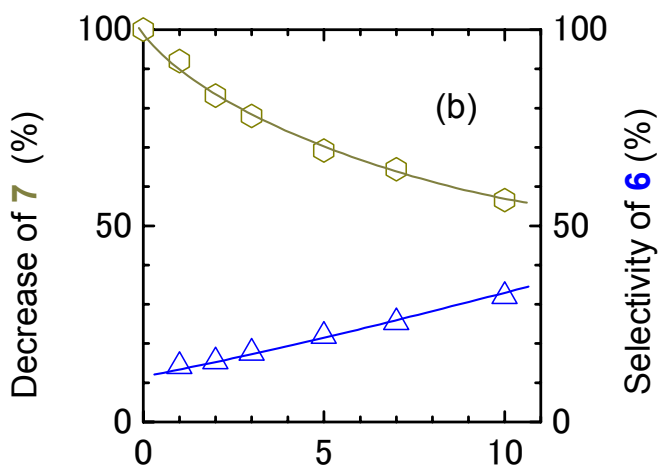

Number of laser shots

Figure S3. KrF excimer laser photolysis of dipentyl selenide (5a) and diphenyl diselenide (7) in $n$-hexane. (a) Decrease in dipentyl selenide (5a, $>$ ) and formation of 1-pentene (2a, $\square$ ), $n$-pentane $(3 \mathrm{a}, \bigcirc)$, and $n$-decane $(4 \mathrm{a}, \nabla)$, and (b) decrease in diphenyl diselenide $(7, \bigcirc)$ and formation of benzene $(\mathbf{6}, \triangle)$ as a function of the number of laser shots. Laser: $\mathrm{KrF}$ excimer laser. Concentration: $10^{-3} \mathrm{M}$ in $n$-hexane, optical path: $1 \mathrm{~mm}$, laser fluence: $100 \mathrm{~mJ} \mathrm{~cm}^{-2}$ pulse $^{-1}$, room temperature. Results are the average of at least two independent runs. 


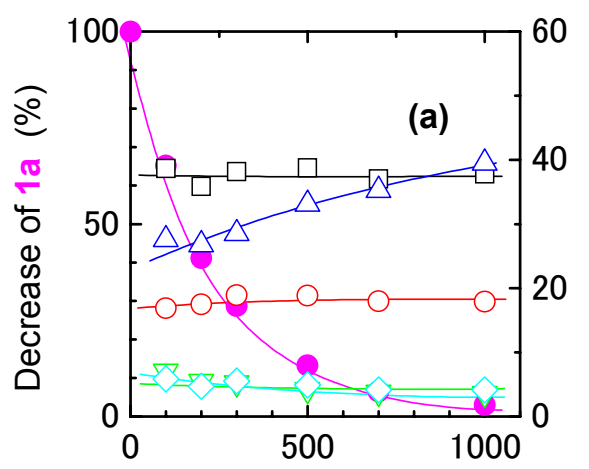

Number of laser shots

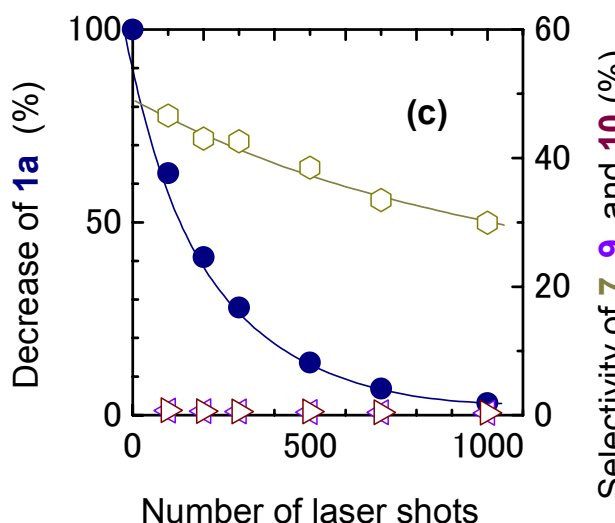

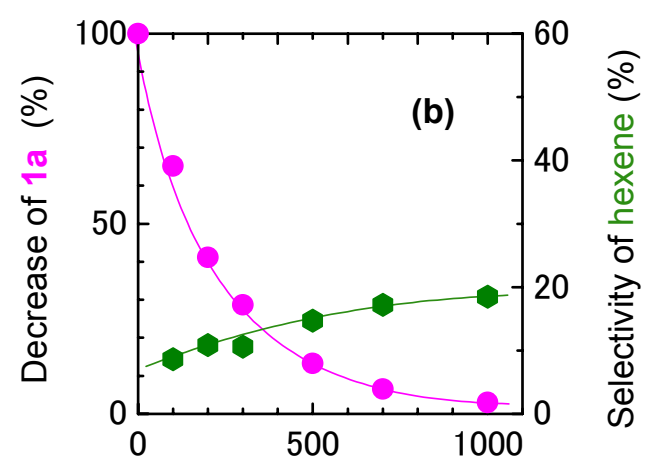

Number of laser shots

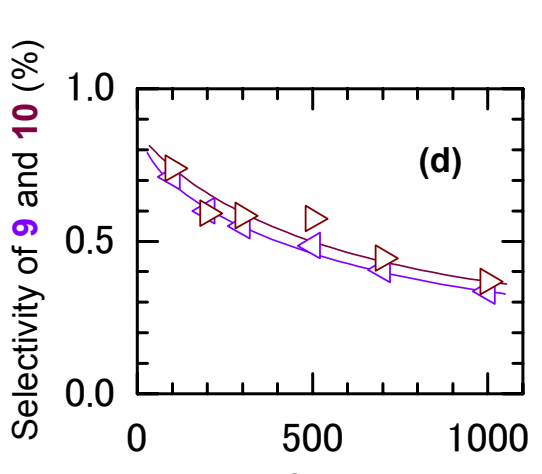

Number of laser shots

Figure S4. $\mathrm{XeCl}$ excimer laser photolysis of pentyl phenyl selenide (1a) in $n$-hexane.

(a) Decrease in $1 \mathbf{a}(\bigcirc)$ and selectivity of 1-pentene $(\mathbf{2} \mathbf{a}, \square)$, n-pentane $(3 \mathbf{a}, \bigcirc), n$-decane (4a, $\nabla$ ), dipentyl selenide $(5 a, \diamond)$, and benzene $(6, \triangle)$ and as a function of the number of laser shots (glc analyses). (b) Decrease in 1a (O) and selectivity of 1-hexene ( ) as a function of the number of laser shots (glc analyses). (c) Decrease in 1a (O), selectivity of diphenyl diselenide (7,, ), 2-pentylphenyl phenyl selenide $(9, \triangleleft)$, and 4-pentylphenyl phenyl selenide $(\mathbf{1 0}, \triangleright)$ as a function of the number of the laser shots (HPLC analyses). (d) Selectivity of 2-pentylphenyl phenyl selenide $(9, \triangleleft)$, and 4-pentylphenyl phenyl selenide $(\mathbf{1 0}, \triangleright)$ (HPLC analyses) as a function of the number of laser shots. Laser: $\mathrm{XeCl}$ excimer laser. Concentration: $10^{-3} \mathrm{M}$ in $n$-hexane, optical path: $1 \mathrm{~mm}$, laser fluence: $80.5 \mathrm{~mJ} \mathrm{~cm}^{-2}$ pulse $^{-1}$, room temperature. Results are the average of at least two independent runs. 


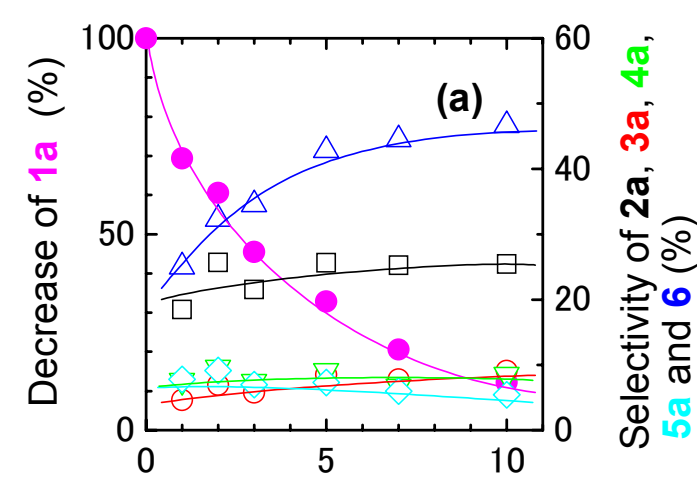

Number of laser shots

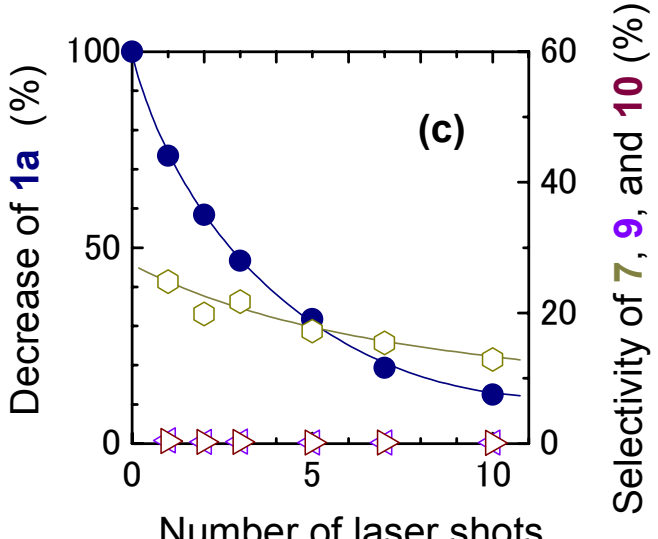

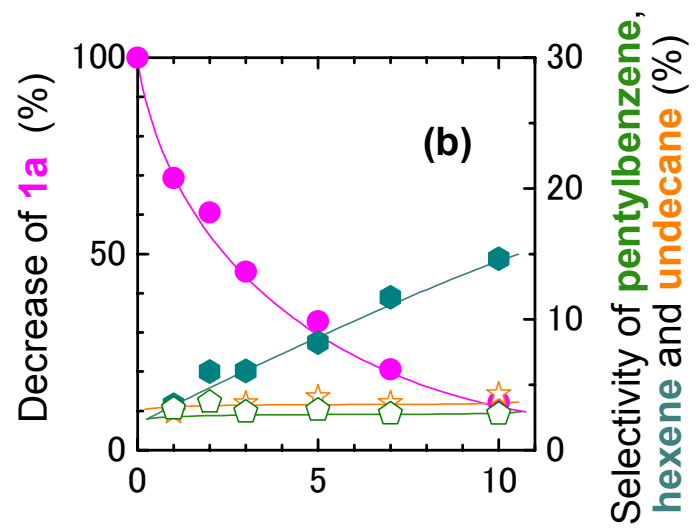

Number of laser shots



Figure S5. ArF excimer laser photolysis of pentyl phenyl selenide (1a) in $n$-hexane. (a) Decrease in 1a ( $\bigcirc$ ) and selectivity of 1-pentene (2a, $\square$ ), $n$-pentane (3a, $\bigcirc$ ), $n$-decane (4a, $\nabla$ ), dipentyl selenide $(5 \mathrm{a}, \diamond)$, and benzene $(6, \triangle)$, as a function of the number of ArF excimer laser shots (glc analyses). (b) Decrease in 1a ( $\bigcirc$ ) and selectivity of pentylbenzene $(\square)$, 1-hexene ( $)$ and undecane ( $\downarrow$ ) as a function of the number of laser shots (glc analyses). (c) Decrease in 1a (๑), selectivity of diphenyl diselenide (7, $)$, 2-pentylphenyl phenyl selenide $(9, \triangleleft)$, and 4-pentylphenyl phenyl selenide $(\mathbf{1 0}, \triangleright)$ as a function of the number of the laser shots (HPLC analyses). (d) Selectivity of 2-pentylphenyl phenyl selenide $(9, \triangleleft)$, and 4-pentylphenyl phenyl selenide $(\mathbf{1 0}, \triangleright)$ (HPLC analyses). Laser: ArF excimer laser. Concentration: $10^{-3} \mathrm{M}$ in $n$-hexane, optical path: $1 \mathrm{~mm}$, laser fluence: $128.5 \mathrm{~mJ} \mathrm{~cm}^{-2}$ pulse $\mathrm{s}^{-1}$, room temperature. Results are the average of at least two independent runs. 


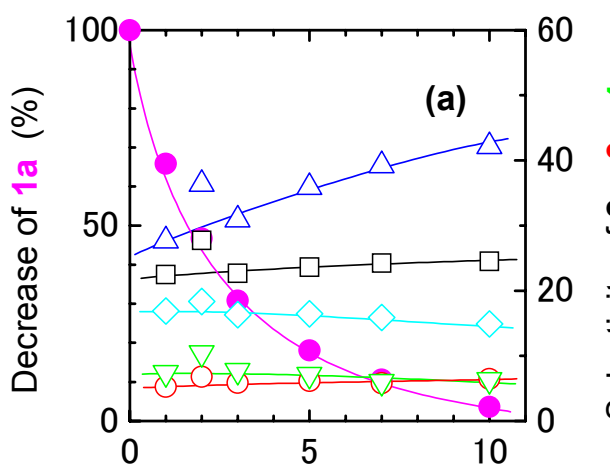

Number of laser shots

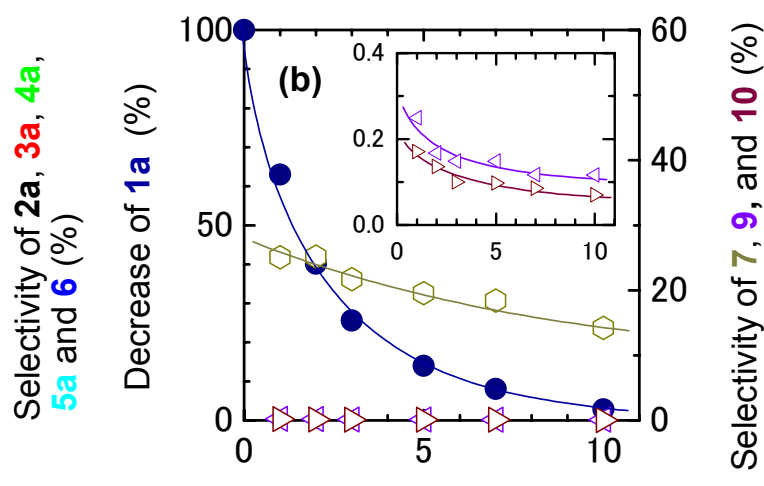

Number of laser shots

Figure S6. KrF excimer laser photolysis of pentyl phenyl selenide (1a) in $n$-heptane.

(a) Decrease in 1a ( $)$ and selectivity of 1-pentene (2a, $\square), n$-pentane (3a, $\bigcirc), n$-decane (4a, $\nabla$ ), dipentyl selenide $(5 a, \diamond)$, and benzene $(6, \triangle)$ as a function of the number of the laser shots (glc analyses). (b) Decrease in 1a ( $\bigcirc)$, selectivity of diphenyl diselenide $(7, \bigcirc)$, 2-pentylphenyl phenyl selenide $(9, \triangleleft)$, and 4-pentylphenyl phenyl selenide $(\mathbf{1 0}, \triangleright)$ as a function of the number of the laser shots (HPLC analyses). Laser: $\mathrm{KrF}$ excimer laser. Concentration: $10^{-3} \mathrm{M}$ in $n$-heptane, optical path: $1 \mathrm{~mm}$, laser fluence: $100 \mathrm{~mJ} \mathrm{~cm} \mathrm{culse}^{-1}$, room temperature. Results are the average of at least two independent runs.

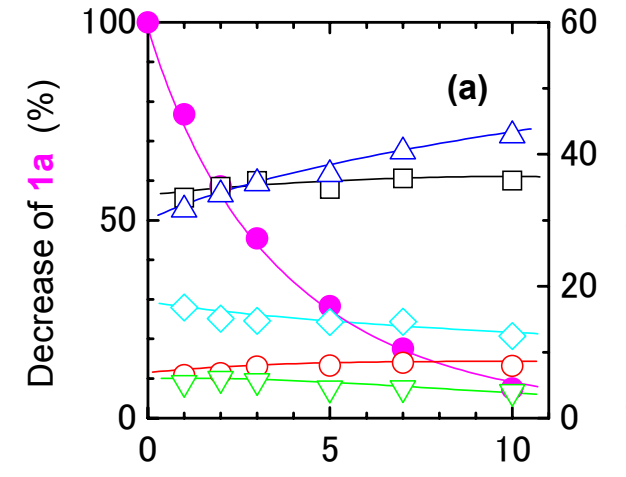

Number of laser shots

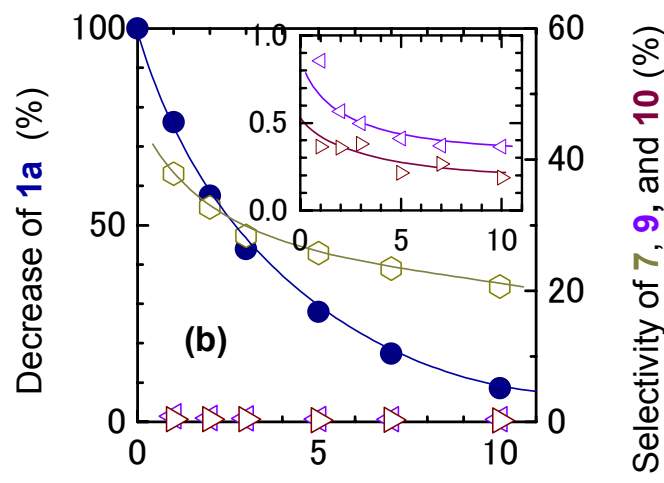

Number of laser shots

Figure S7. KrF excimer laser photolysis of pentyl phenyl selenide (1a) in $n$-dodecane.

(a) Decrease in 1a ( $\bigcirc)$ and selectivity of 1-pentene (2a, $\square), n$-pentane (3a, $\bigcirc), n$-decane (4a, $\nabla$ ), dipentyl selenide $(5 a, \diamond)$, and benzene $(6, \triangle)$ as a function of the number of laser shots (glc analyses). (b) Decrease in 1a $(\bigcirc)$, selectivity of diphenyl diselenide $(7, \bigcirc)$, 2-pentylphenyl phenyl selenide $(9, \triangleleft)$, and 4-pentylphenyl phenyl selenide $(\mathbf{1 0}, \triangleright)$ as a function of the number of the laser shots (HPLC analyses). Laser: $\mathrm{KrF}$ excimer laser. Concentration: $10^{-3} \mathrm{M}$ in $n$-dodecane, optical path: $1 \mathrm{~mm}$, laser fluence: $100 \mathrm{~mJ} \mathrm{~cm}{ }^{-2}$ pulse $\mathrm{s}^{-1}$, room temperature. Results are the average of at least two independent runs. 

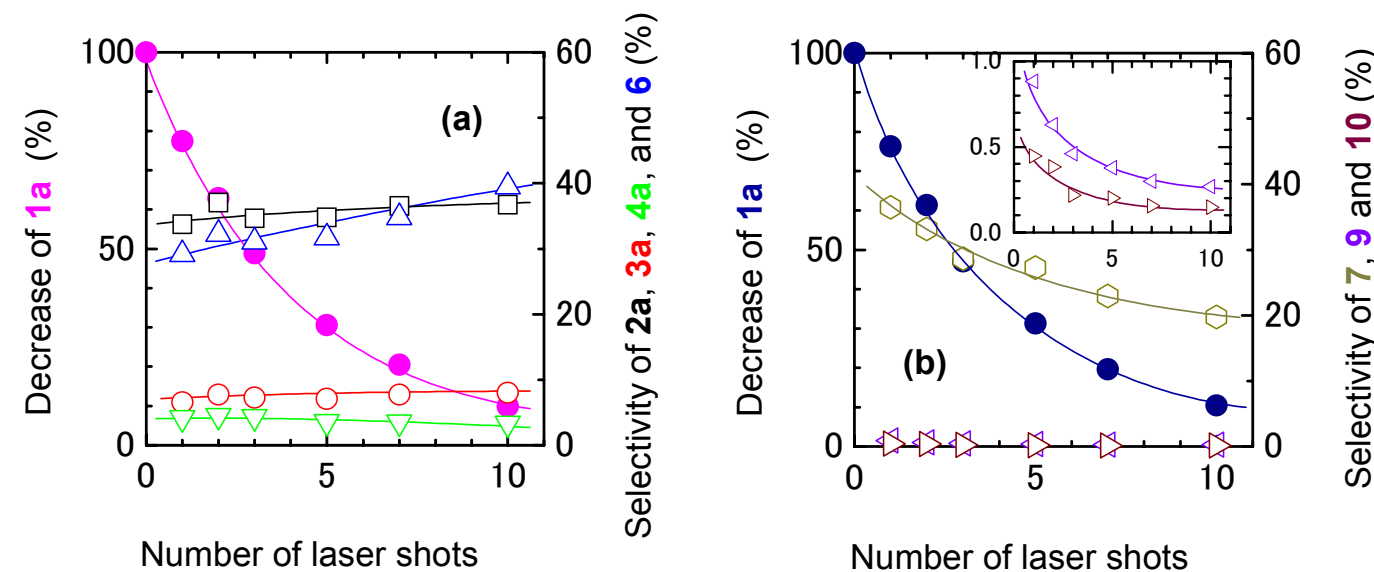

Figure S8. KrF excimer laser photolysis of pentyl phenyl selenide (1a) in $n$-tetradecane.

(a) Decrease in 1a ( $\bigcirc$ ) and selectivity of 1-pentene (2a, $\square$ ), n-pentane (3a, $\bigcirc$ ), $n$-decane (4a, $\nabla$ ), and benzene $(6, \triangle)$ as a function of the number of laser shots (glc analyses). (b) Decrease in 1a ( ), selectivity of diphenyl diselenide $(7, \bigcirc), 2$-pentylphenyl phenyl selenide $(9, \triangleleft)$, and 4-pentylphenyl phenyl selenide $(\mathbf{1 0}, \triangleright)$ as a function of the number of the laser shots (HPLC analyses). Laser: $\mathrm{KrF}$ excimer laser. Concentration: $10^{-3} \mathrm{M}$ in $n$-tetradecane, optical path: $1 \mathrm{~mm}$, laser fluence: $100 \mathrm{~mJ} \mathrm{~cm}^{-2}$ pulse $\mathrm{s}^{-1}$, room temperature. Results are the average of at least two independent runs.

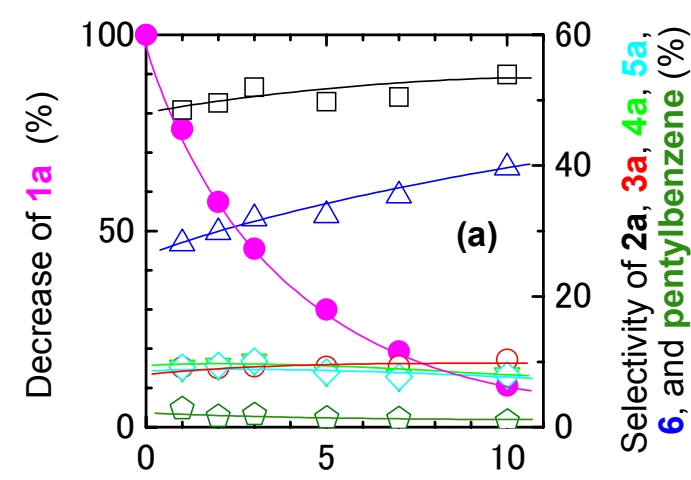

Number of laser shots

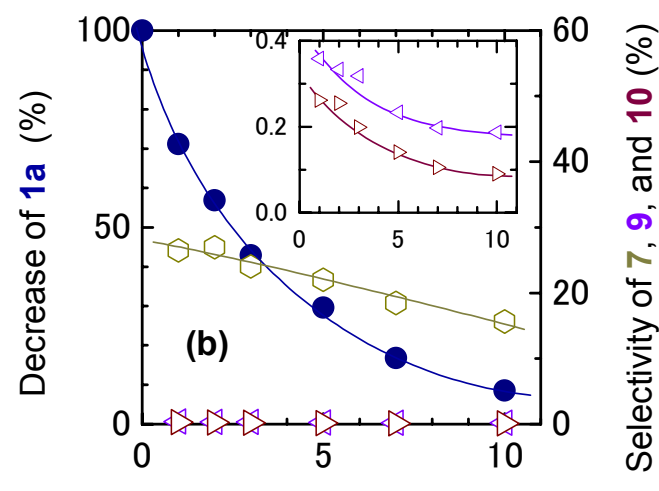

Number of laser shots

Figure S9. KrF excimer laser photolysis of pentyl phenyl selenide (1a) in $n$-hexadecane.

(a) Decrease in $1 \mathrm{a}(\bigcirc)$ and selectivity of 1 -pentene $(\mathbf{2} \mathbf{a}, \square), n$-pentane (3a, $\bigcirc), n$-decane (4a, $\nabla$ ), dipentyl selenide $(5 \mathrm{a}, \diamond)$, benzene $(6, \triangle)$, and pentylbenzene $(\triangle)$ as a function of the number of laser shots (glc analyses). (b) Decrease in 1a ( $(\mathcal{)}$ ), selectivity of diphenyl diselenide $(7, \oslash), 2$-pentylphenyl phenyl selenide $(9, \triangleleft)$, and 4-pentylphenyl phenyl selenide $(\mathbf{1 0}, \triangleright)$ as a function of the number of the laser shots (HPLC analyses). Laser: KrF excimer laser.

Concentration: $10^{-3} \mathrm{M}$ in $n$-hexadecane, optical path: $1 \mathrm{~mm}$, laser fluence: $100 \mathrm{~mJ} \mathrm{~cm}^{-2} \mathrm{pulse}^{-1}$, room temperature. Results are the average of at least two independent runs. 




Number of laser shots

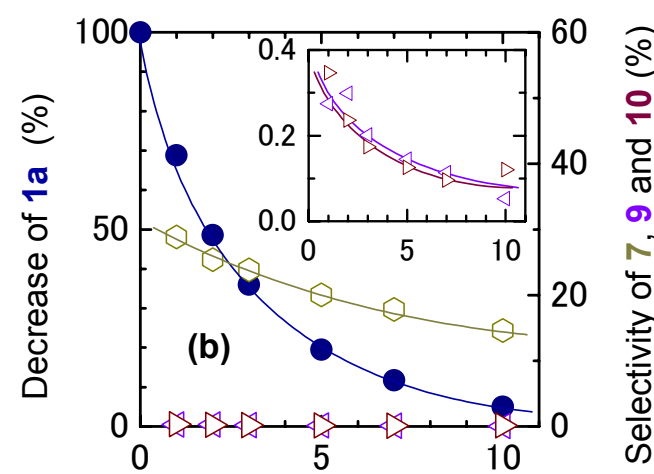

Number of laser shots

Figure S10. KrF excimer laser photolysis of pentyl phenyl selenide (1a) in cyclopentane.

(a) Decrease in 1a ( $\odot$ ) and selectivity of 1-pentene (2a, $\square$ ), n-pentane (3a, $\bigcirc), n$-decane (4a, $\nabla$ ), dipentyl selenide $(5 a, \diamond)$, and benzene $(\mathbf{6}, \triangle$ ) as a function of the number of laser shots (glc analyses). (b) Decrease in 1a ( ), selectivity of diphenyl diselenide $(7, \bigcirc)$, 2-pentylphenyl phenyl selenide $(9, \triangleleft)$, and 4-pentylphenyl phenyl selenide $(\mathbf{1 0}, \triangleright)$ as a function of the number of the laser shots (HPLC analyses). Laser: KrF excimer laser.

Concentration: $10^{-3} \mathrm{M}$ in cyclopentane, optical path: $1 \mathrm{~mm}$, laser fluence: $100 \mathrm{~mJ} \mathrm{~cm} \mathrm{culse}^{-1}$, room temperature. Results are the average of at least two independent runs.

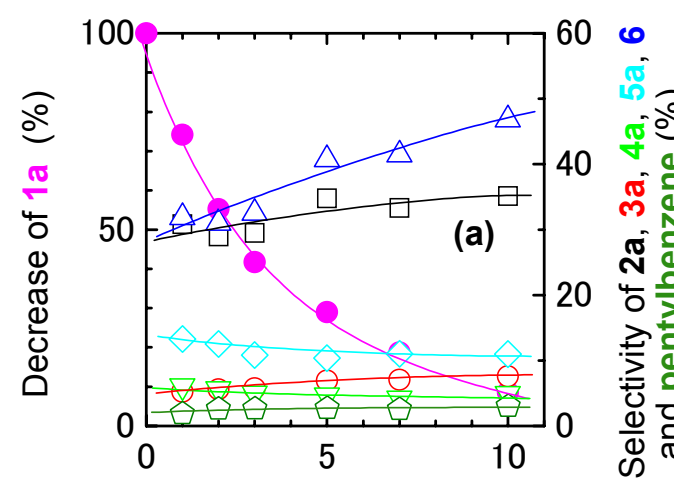

Number of laser shots

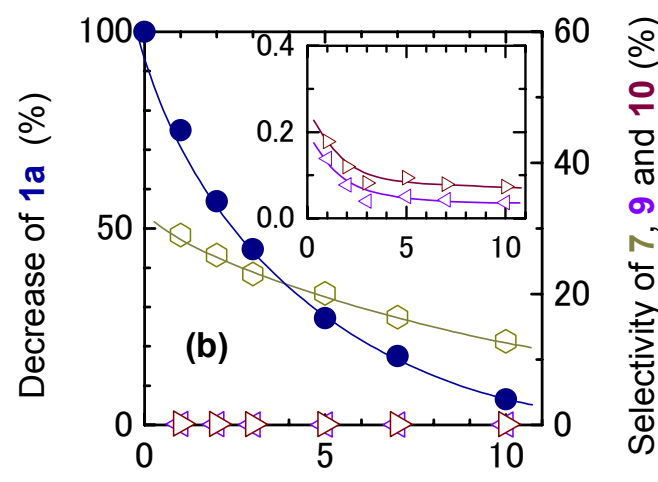

Number of laser shots

Figure S11. KrF excimer laser photolysis of pentyl phenyl selenide (1a) in cyclohexane. (a) Decrease in 1a ( $)$ and selectivity of 1-pentene (2a, $\square), n$-pentane (3a, $\bigcirc), n$-decane (4a, $\nabla$ ), dipentyl selenide $(5 \mathrm{a}, \diamond)$, benzene $(6, \triangle)$, and pentylbenzene pentylbenzene $(\triangle)$ as a function of the number of laser shots (glc analyses). (b) Decrease in 1a (O), selectivity of diphenyl diselenide $(7, \bigcirc)$, 2-pentylphenyl phenyl selenide $(9, \triangleleft)$, and 4-pentylphenyl phenyl selenide $(10, \triangleright)$ as a function of the number of the laser shots (HPLC analyses). Laser: KrF excimer laser. Concentration: $10^{-3} \mathrm{M}$ in cyclohexane, optical path: $1 \mathrm{~mm}$, laser fluence: $100 \mathrm{~mJ} \mathrm{~cm}{ }^{-2}$ pulse $^{-1}$, room temperature. Results are the average of at least two independent runs. 


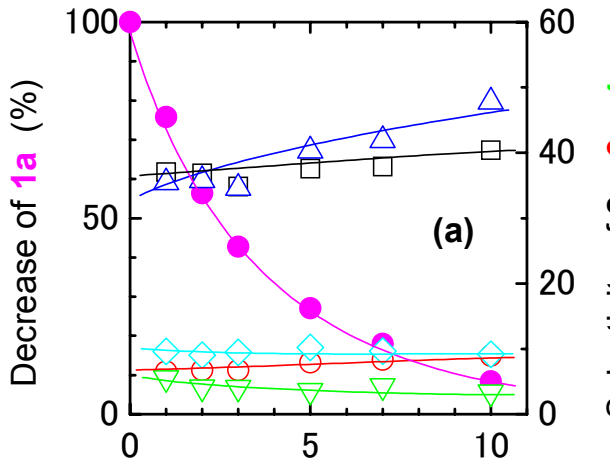

Number of laser shots

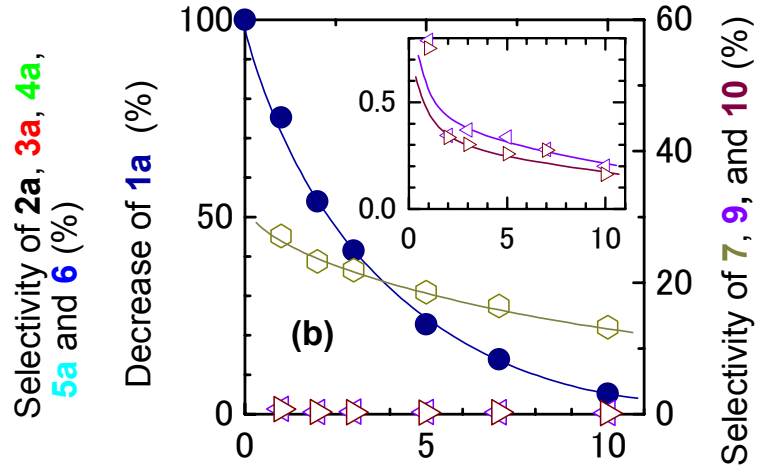

Number of laser shots

Figure S12. KrF excimer laser photolysis of pentyl phenyl selenide (1a) in cycloheptane.

(a) Decrease in 1a ( $\odot$ ) and selectivity of 1-pentene (2a, $\square$ ), n-pentane (3a, $\bigcirc), n$-decane (4a, $\nabla$ ), dipentyl selenide $(5 \mathrm{a}, \diamond)$, and benzene $(\mathbf{6}, \triangle)$ as a function of the number of laser shots (glc analyses). (b) Decrease in 1a ( ), selectivity of diphenyl diselenide $(7, \bigcirc)$, 2-pentylphenyl phenyl selenide $(9, \triangleleft)$, and 4-pentylphenyl phenyl selenide $(\mathbf{1 0}, \triangleright)$ as a function of the number of the laser shots (HPLC analyses). Laser: $\mathrm{KrF}$ excimer laser.

Concentration: $10^{-3} \mathrm{M}$ in cycloheptane, optical path: $1 \mathrm{~mm}$, laser fluence: $100 \mathrm{~mJ} \mathrm{~cm} \mathrm{culse}^{-1}$, room temperature. Results are the average of at least two independent runs.

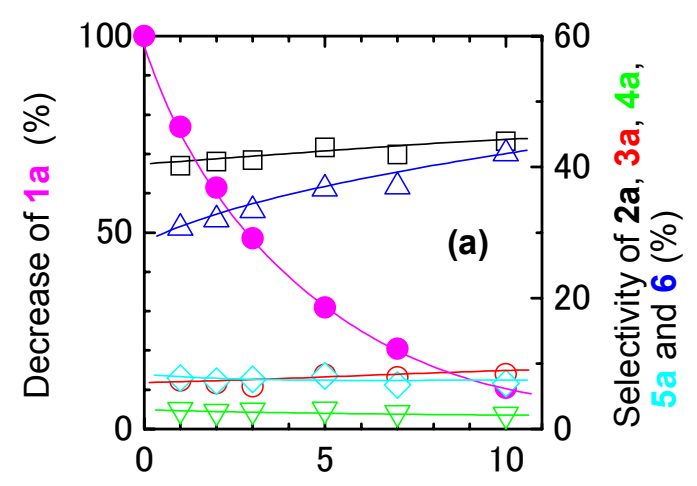

Number of laser shots

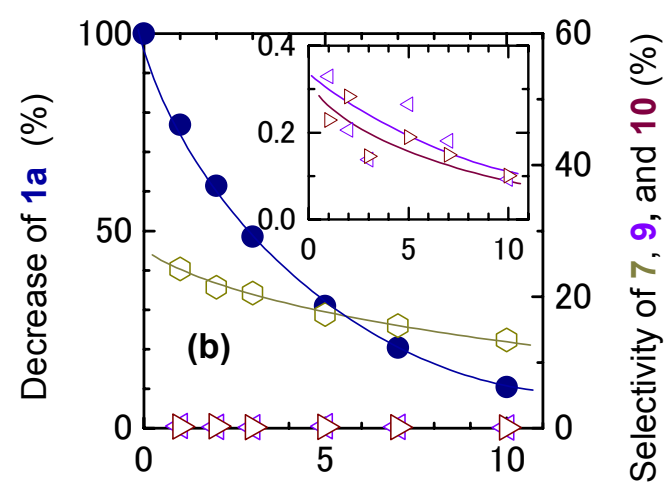

Number of laser shots

Figure S13. KrF excimer laser photolysis of pentyl phenyl selenide (1a) in cyclooctane.

(a) Decrease in $1 \mathbf{a}(\bigcirc)$ and selectivity of 1-pentene (2a, $\square), n$-pentane (3a, $\bigcirc$ ), $n$-decane (4a, $\nabla)$, benzene $(6, \triangle)$, and dipentyl selenide $(5 \mathrm{a}, \diamond)$ as a function of the number of laser shots (glc analyses). (b) Decrease in 1a ( $(0)$, selectivity of diphenyl diselenide $(7, \oslash)$, 2-pentylphenyl phenyl selenide $(9, \triangleleft)$, and 4-pentylphenyl phenyl selenide $(\mathbf{1 0}, \triangleright)$ as a function of the number of the laser shots (HPLC analyses). Laser: KrF excimer laser.

Concentration: $10^{-3} \mathrm{M}$ in cyclooctane, optical path: $1 \mathrm{~mm}$, laser fluence: $100 \mathrm{~mJ} \mathrm{~cm}^{-2}$ pulse $\mathrm{s}^{-1}$, room temperature. Results are the average of at least two independent runs. 


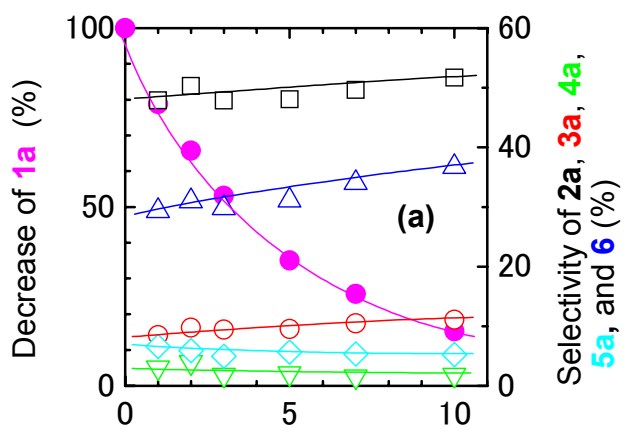

Number of laser shots

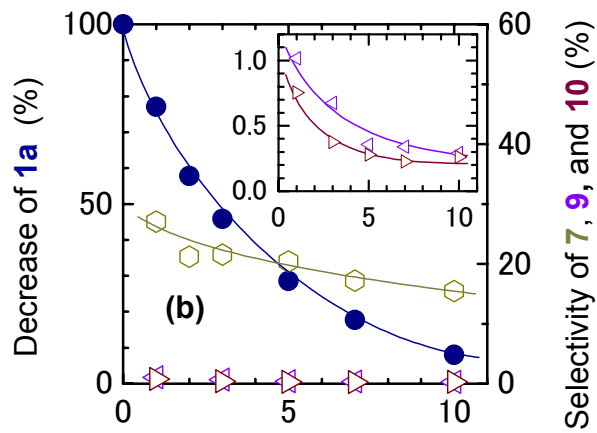

Number of laser shots

Figure S14. KrF excimer laser photolysis of pentyl phenyl selenide (1a) in cyclodecane.

(a) Decrease in 1a ( $\bigcirc)$ and selectivity of 1-pentene (2a, $\square), n$-pentane (3a, $\bigcirc), n$-decane (4a, $\nabla)$, benzene $(6, \triangle)$, and dipentyl selenide $(5 a, \diamond)$ as a function of the number of laser shots (glc analyses). (b) Decrease in $\mathbf{1 a}(\bigcirc)$, selectivity of diphenyl diselenide $(7, \bigcirc)$, 2-pentylphenyl phenyl selenide $(9, \triangleleft)$, and 4-pentylphenyl phenyl selenide $(\mathbf{1 0}, \triangleright)$ as a function of the number of the laser shots (HPLC analyses). Laser: $\mathrm{KrF}$ excimer laser. Concentration: $10^{-3} \mathrm{M}$ in cyclodecane, optical path: $1 \mathrm{~mm}$, laser fluence: $100 \mathrm{~mJ} \mathrm{~cm} \mathrm{culs}^{-1}$, room temperature. Results are the average of at least two independent runs.
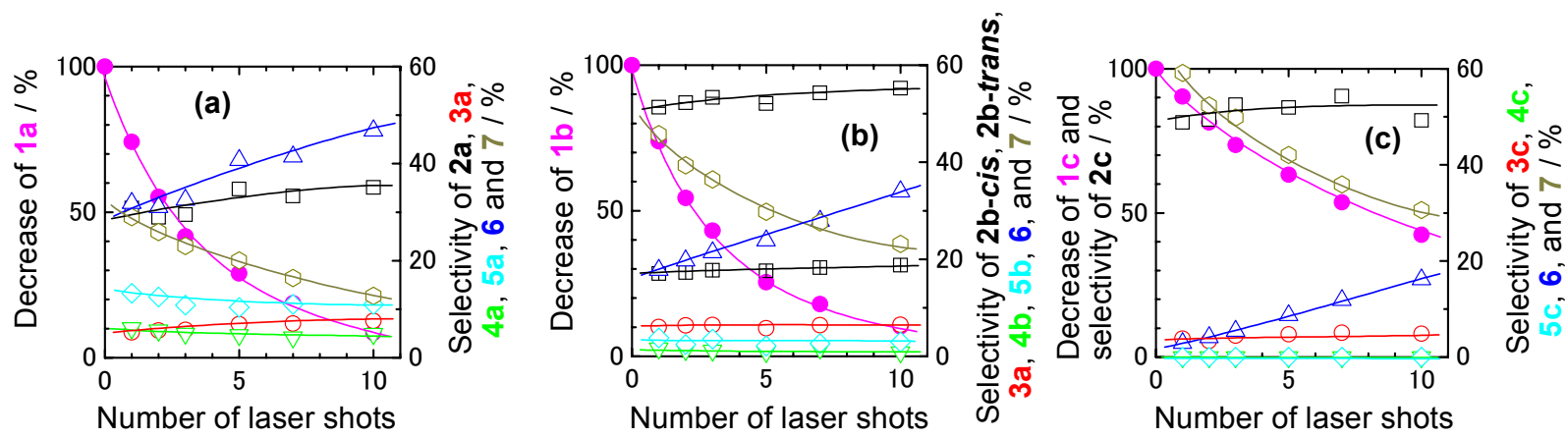

Figure S15. KrF excimer laser photolysis of $n$-pentyl phenyl selenide (1a), 1-ethylpropyl phenyl selenide (1b), and tert-butyl phenyl selenide (1c). (a) Decrease in 1a (O) and selectivity of 1-pentene (2a, $\square$ ), $n$-pentane (3a, $\bigcirc)$, $n$-decane (4a, $\nabla$ ), dipentyl selenide (5a, $\diamond)$, benzene (6, $\triangle$ ), and diphenyl diselenide $(7, \bigcirc),(\mathrm{b})$ decrease in $\mathbf{1 b}(\bigcirc)$ and selectivity of cis-2-pentene (2b-cis, $\boxminus)$, trans-2-pentene (2b-trans, $\square)$, $n$-pentane (3a, $\bigcirc)$, 3,4-diethylhexane (4b, $\nabla)$, bis(1-ethylpropyl) selenide $(5 \mathrm{~b}, \diamond)$, benzene $(6, \triangle)$, and diphenyl diselenide $(7, \bigcirc)$, and (c) decrease in 1c ( $\bigcirc)$ and selectivity of 2-methylpropene $(\mathbf{2 c}, \square)$, 2-methylpropane $(3 \mathbf{c}, \bigcirc)$, 2,2,3,3-tetramethylbutane (4c, $\nabla)$, bis(1,1-dimethylethyl) selenide $(5 \mathrm{c}, \diamond)$, benzene $(6, \triangle)$, and diphenyl diselenide $(7, \bigcirc)$ in the $\mathrm{KrF}$ excimer laser photolyses as a function of the number of laser shots. Concentration: $10^{-3} \mathrm{M}$ in cyclohexane, optical path: $1 \mathrm{~mm}$, laser fluence: $100 \mathrm{~mJ} \mathrm{~cm}^{-2}$ pulse $\mathrm{s}^{-1}$, room temperature. Results are the average of at least two independent runs. 

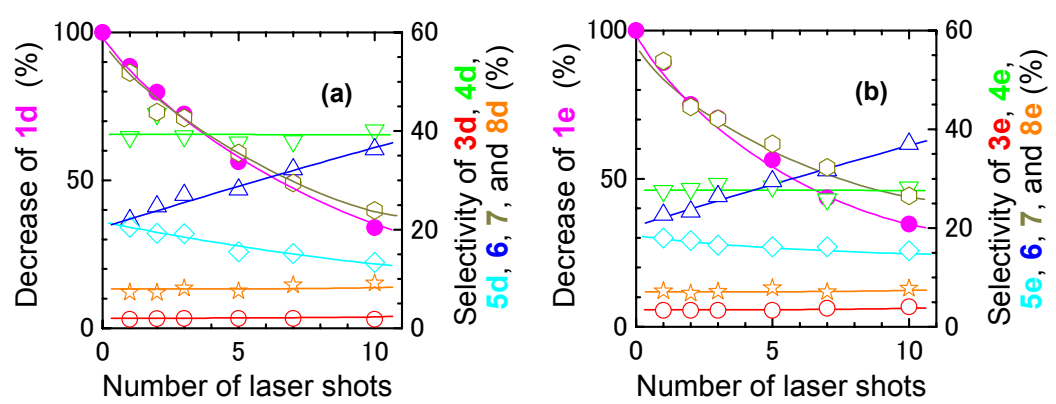

Figure S16. KrF excimer laser photolysis of allyl phenyl selenide (1d) and 2-methylallyl phenyl selenides (1e). (a) Decrease in $\mathbf{1 d}\left({ }^{\circ}\right)$ and selectivity of propene $(\mathbf{3 d}, \bigcirc)$, 1,5-hexadiene ( $4 \mathbf{d}$, $\nabla)$, diallyl selenide $(5 \mathrm{~d}, \diamond)$, benzene $(6, \triangle)$, diphenyl diselenide $(7, \bigcirc)$, and allylcyclohexane $(8 \mathrm{~d}, \boldsymbol{\zeta})$, and (b) decrease in $1 \mathrm{e}\left({ }^{\circ}\right)$ and selectivity of 2 -methylpropene $(3 \mathrm{e}, \bigcirc)$, 2,5-dimethyl-1,5-hexadiene (4e, $\nabla$ ), bis(2-methylallyl) selenide (5e, $\diamond)$, benzene $(6, \triangle)$, diphenyl diselenide $(7, \bigcirc)$, and 2-methylallylcyclohexane (8e,,$\hat{\tau})$ in the $\mathrm{KrF}$ excimer laser photolyses as a function of the number of laser shots. Concentration: $10^{-3} \mathrm{M}$ in cyclohexane, optical path: $1 \mathrm{~mm}$, laser fluence: $100 \mathrm{~mJ} \mathrm{~cm}^{-2}$ pulse $^{-1}$, room temperature. Results are the average of at least two independent runs. 
1a $\mathrm{CDCl} 3$ 13C NMR $125 \mathrm{MHz}$






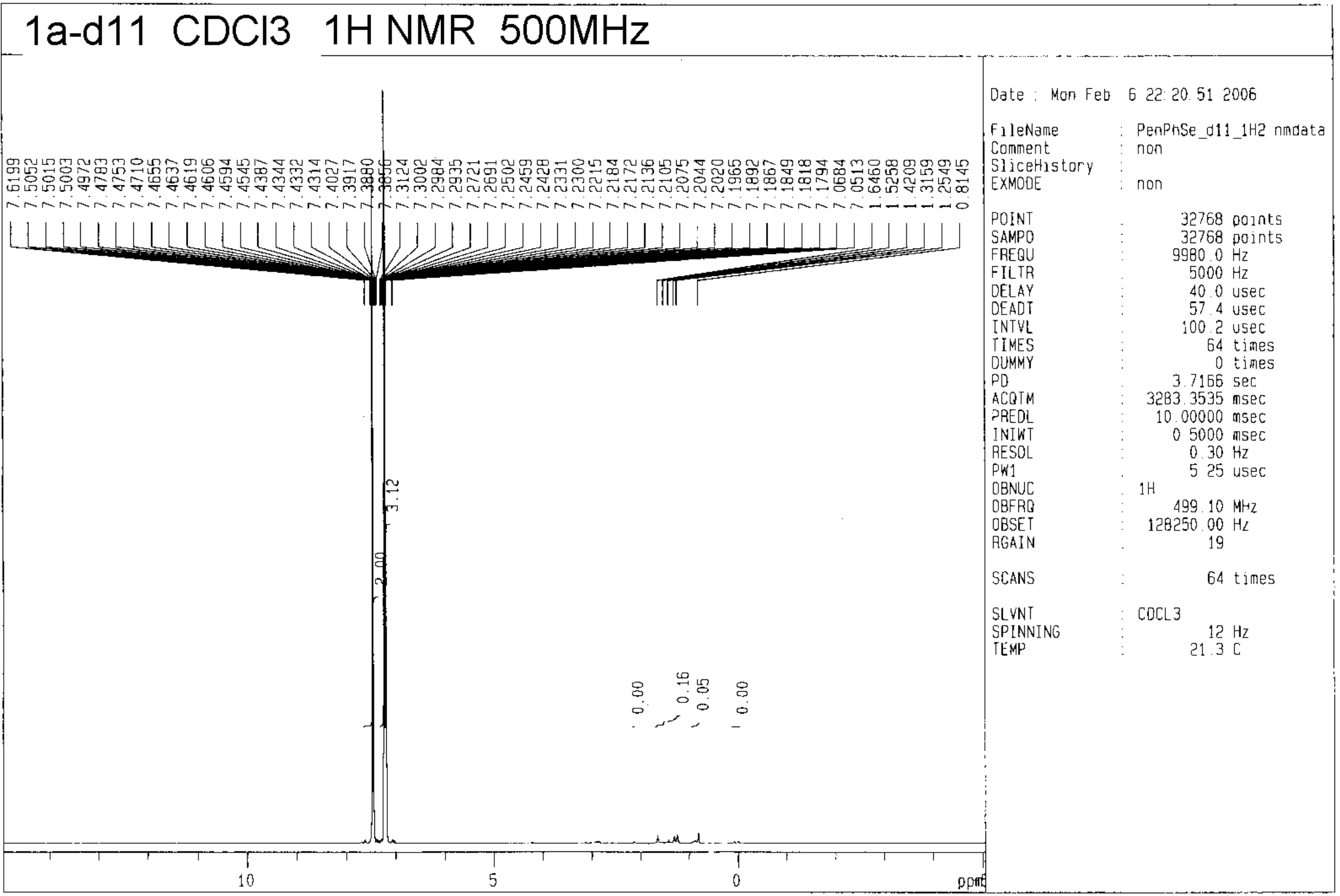

S18 




S19 


\section{1b $\mathrm{CDCl} 3$ 1H NMR $500 \mathrm{MHz}$}

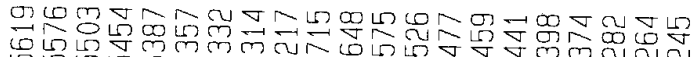

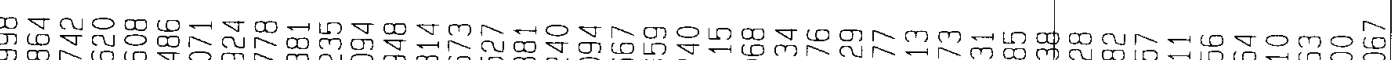

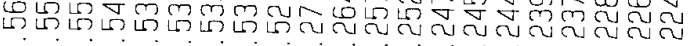

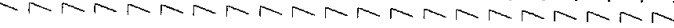
作

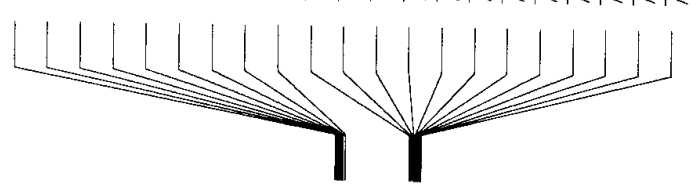

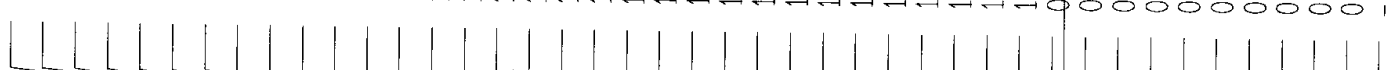
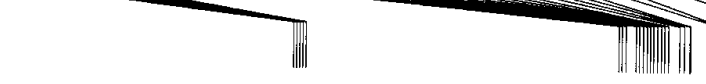

( 1 )

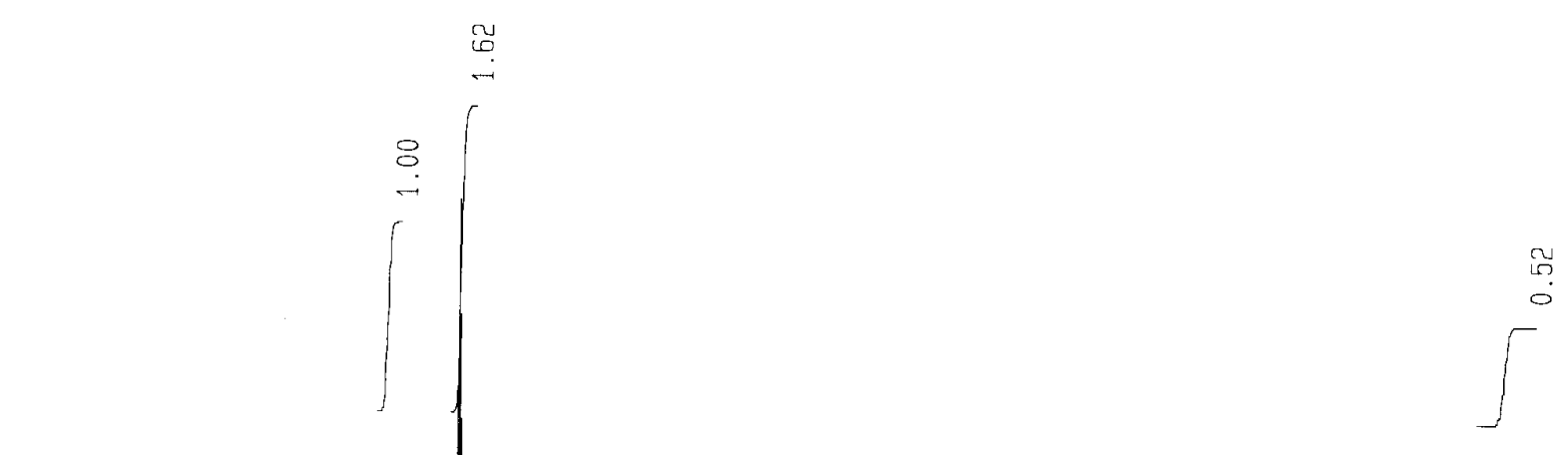




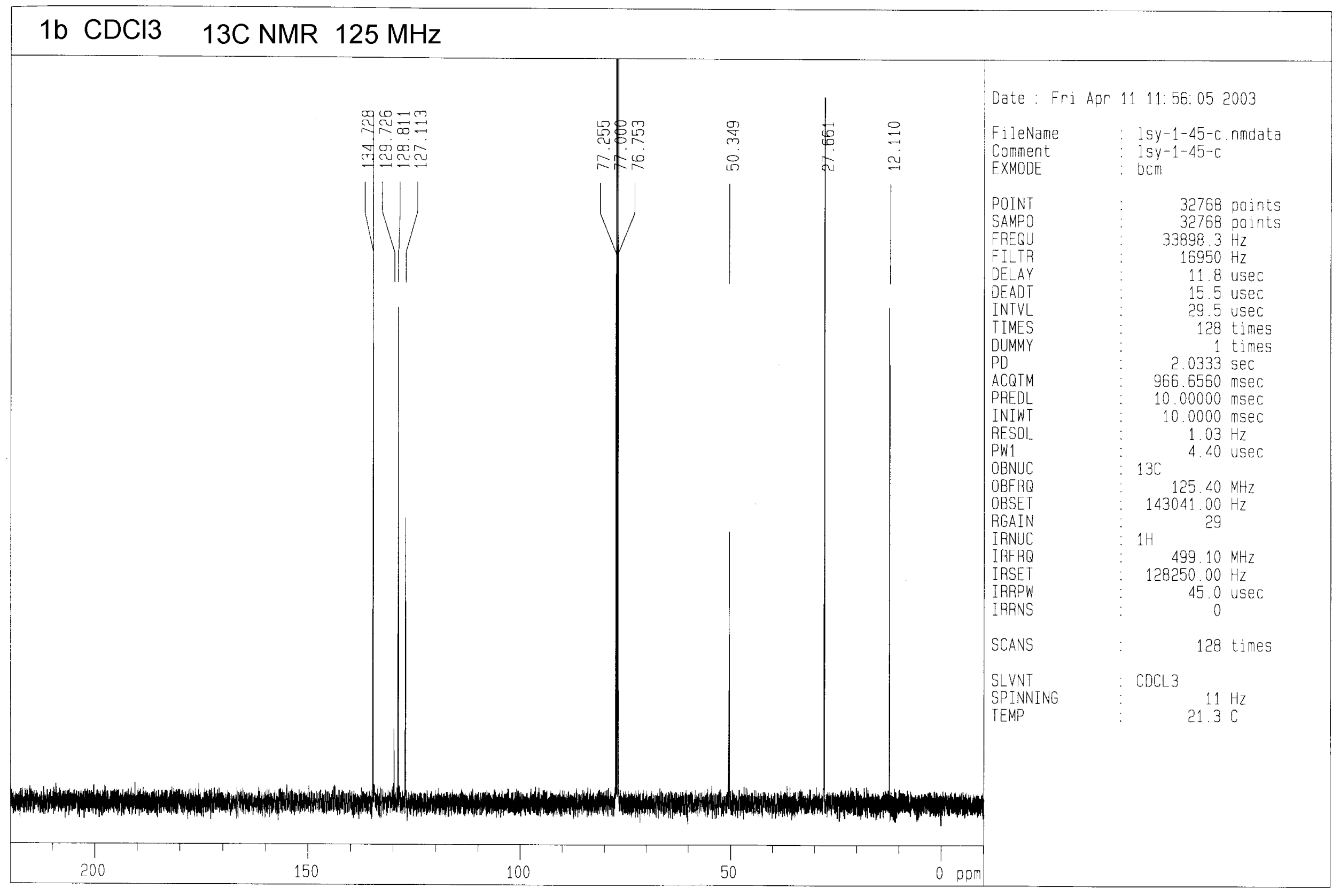




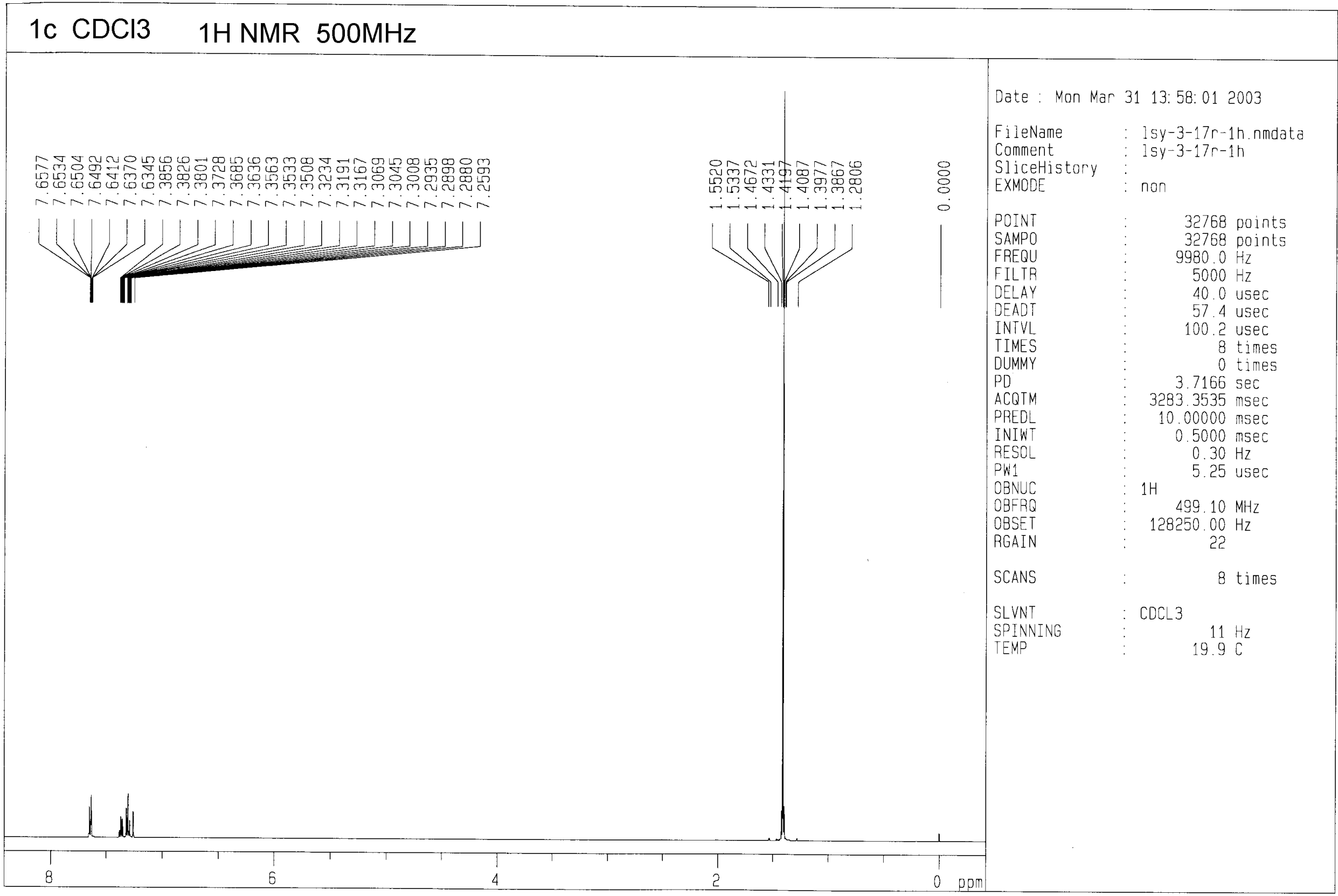




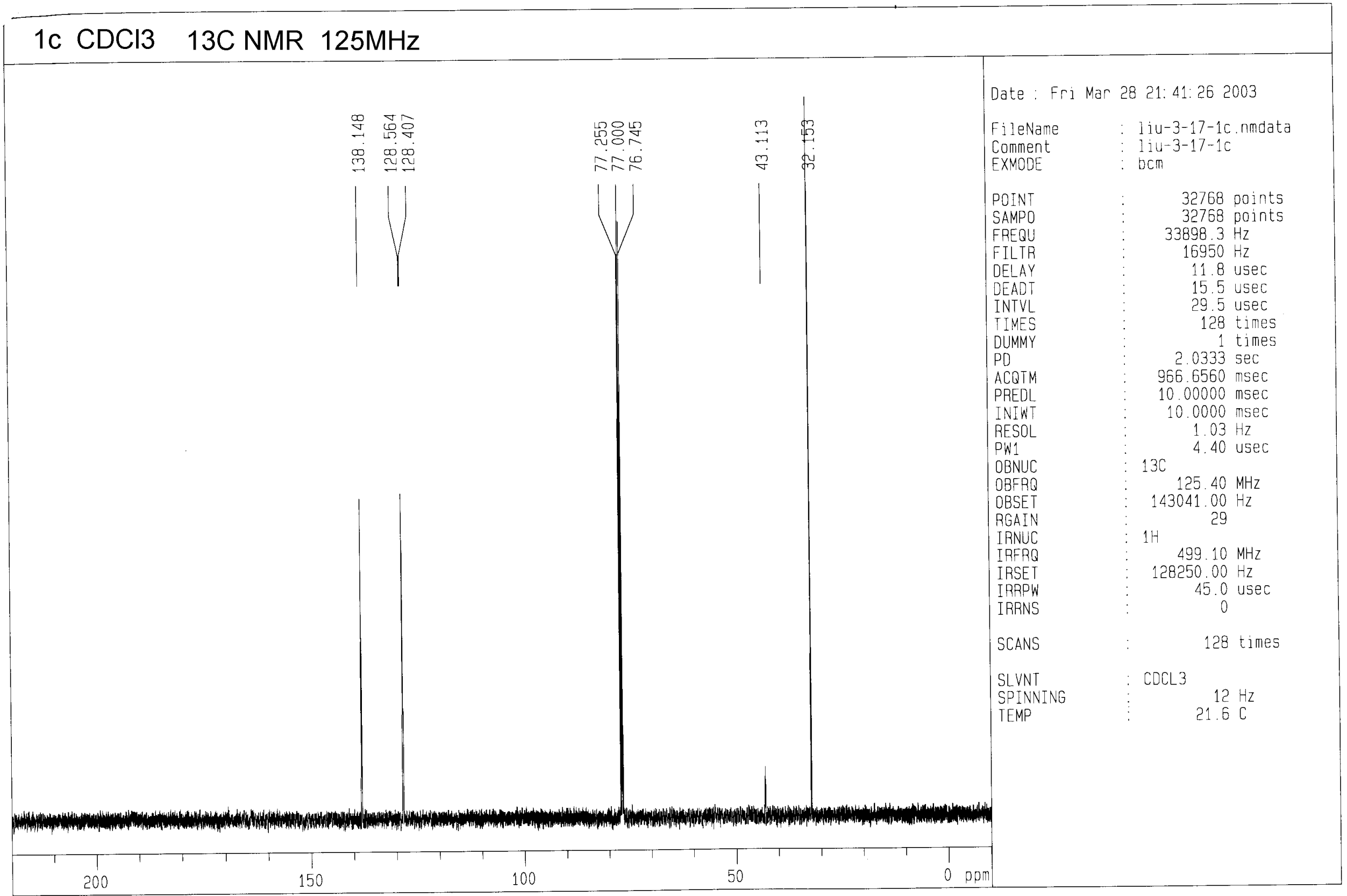

S23 


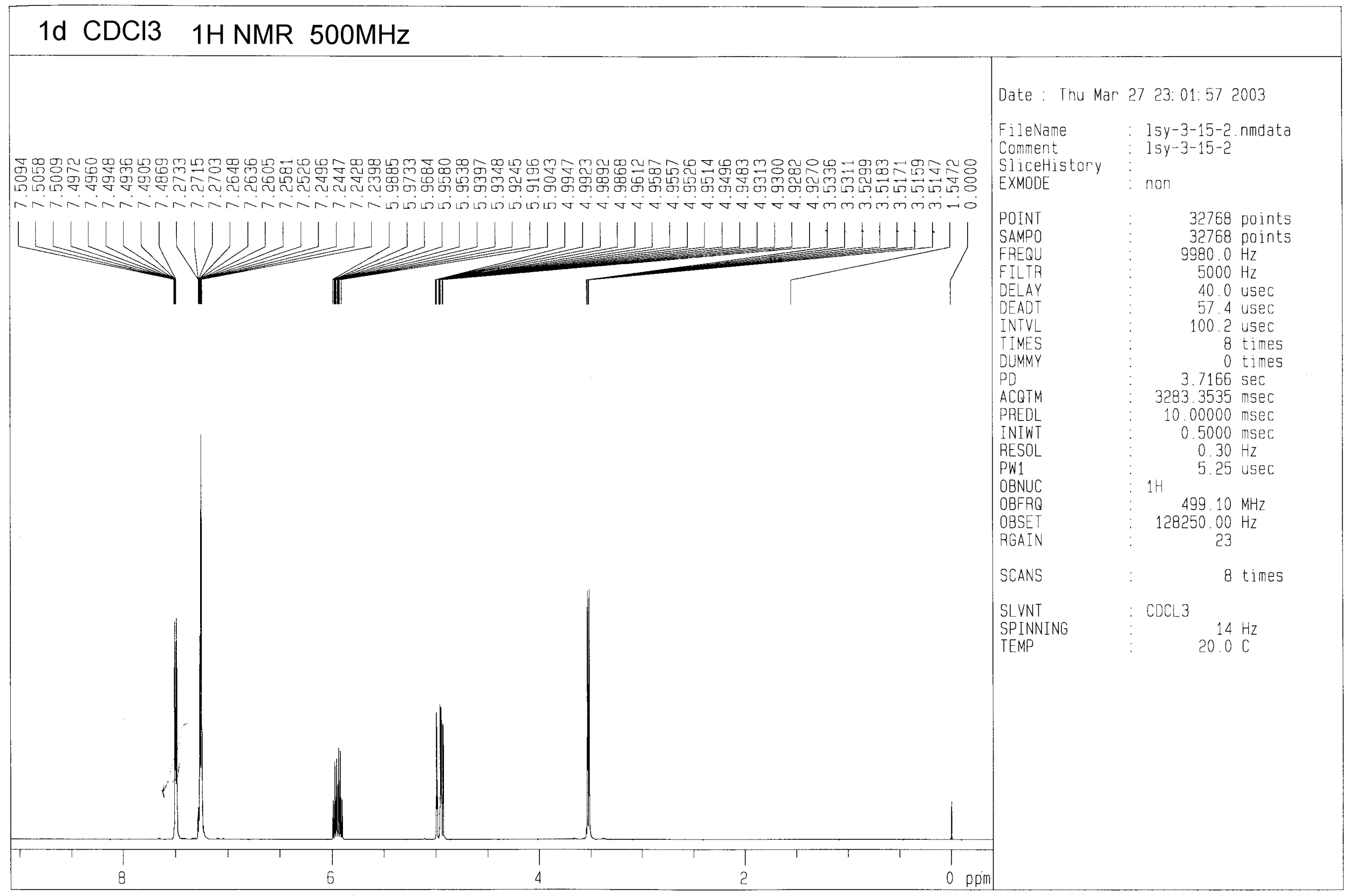


1d $\mathrm{CDCl} 3$ 13C NMR $125 \mathrm{MHz}$






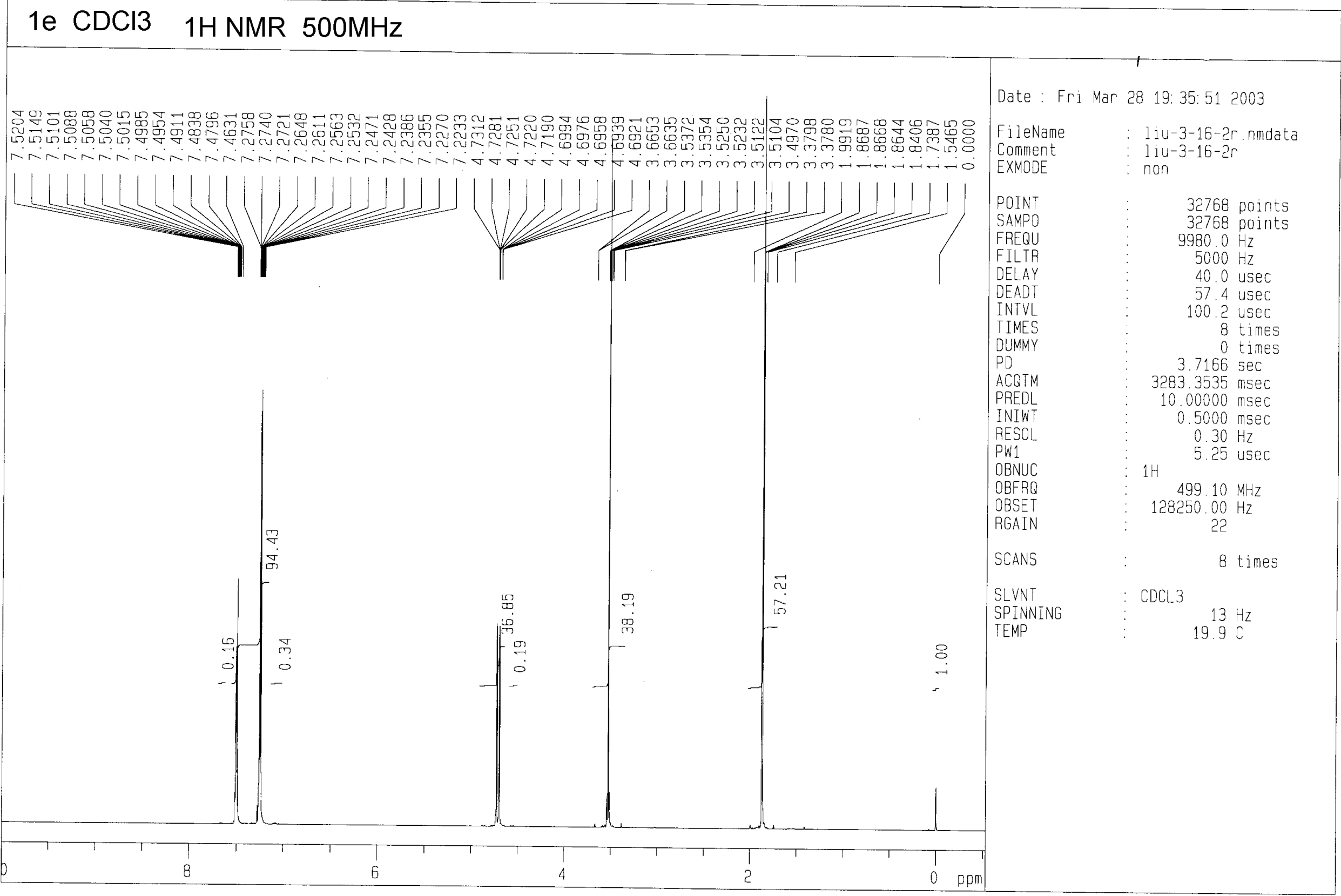




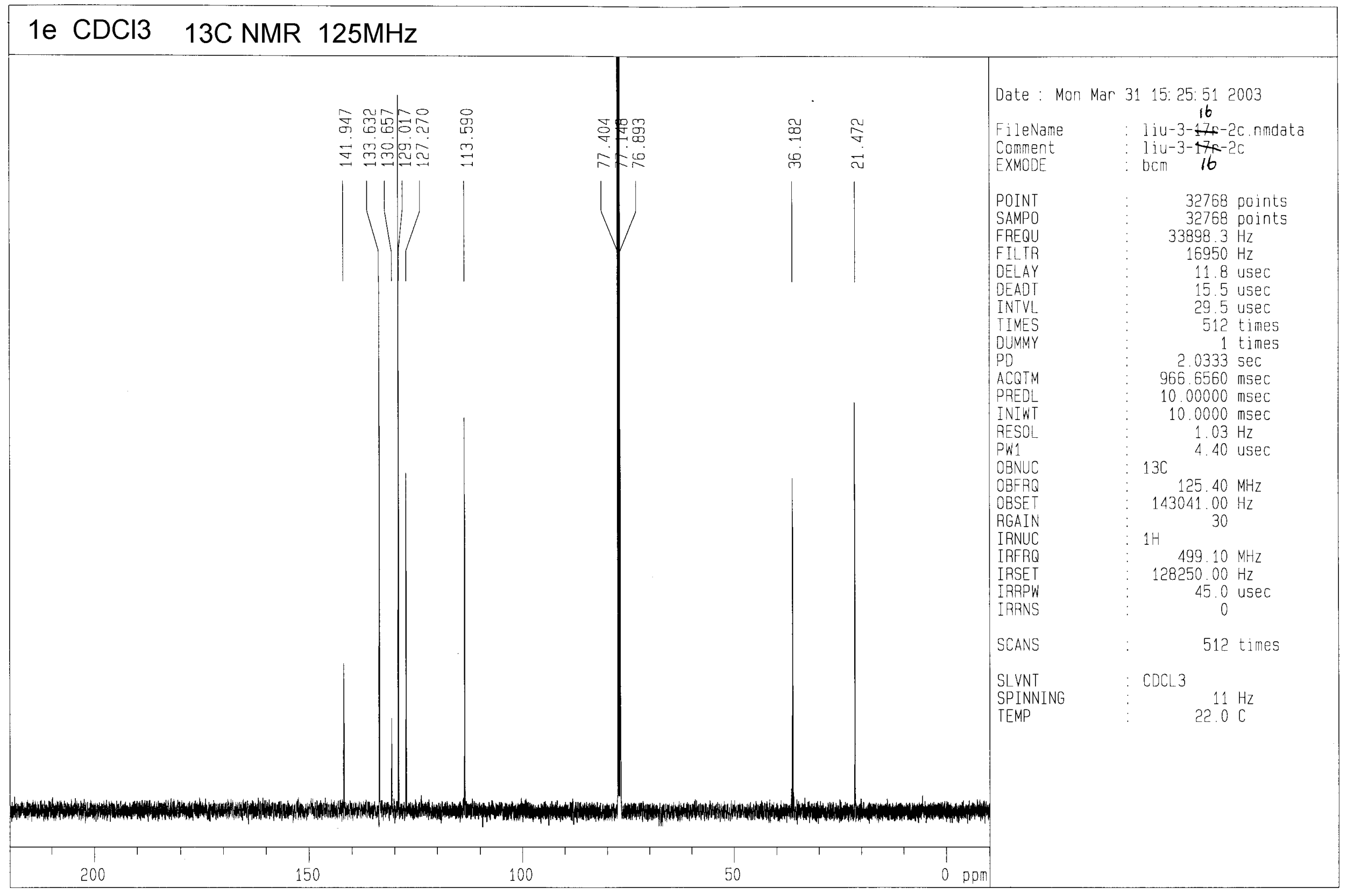




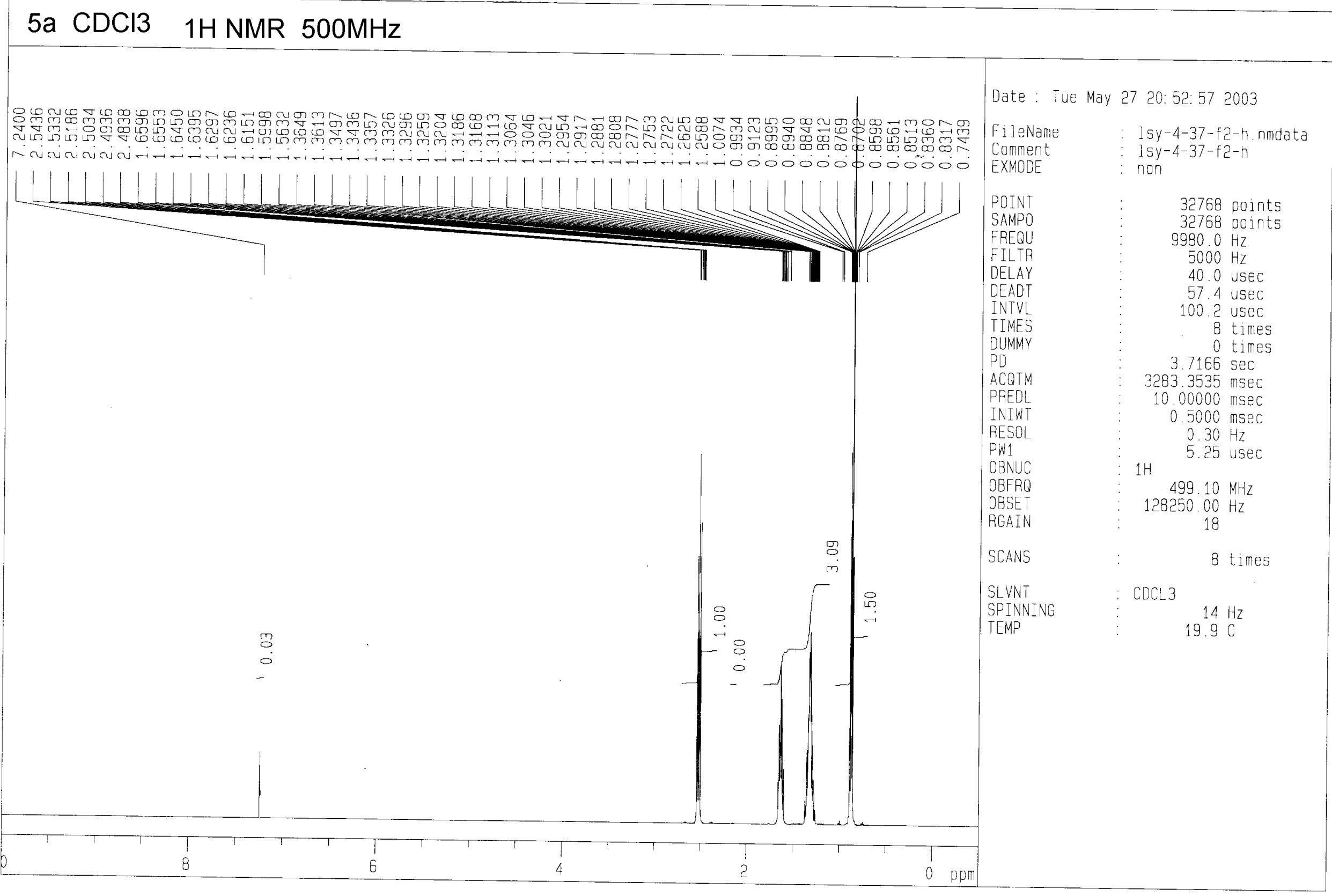









\section{5b CDCl3 1H NMR $500 M H z$}

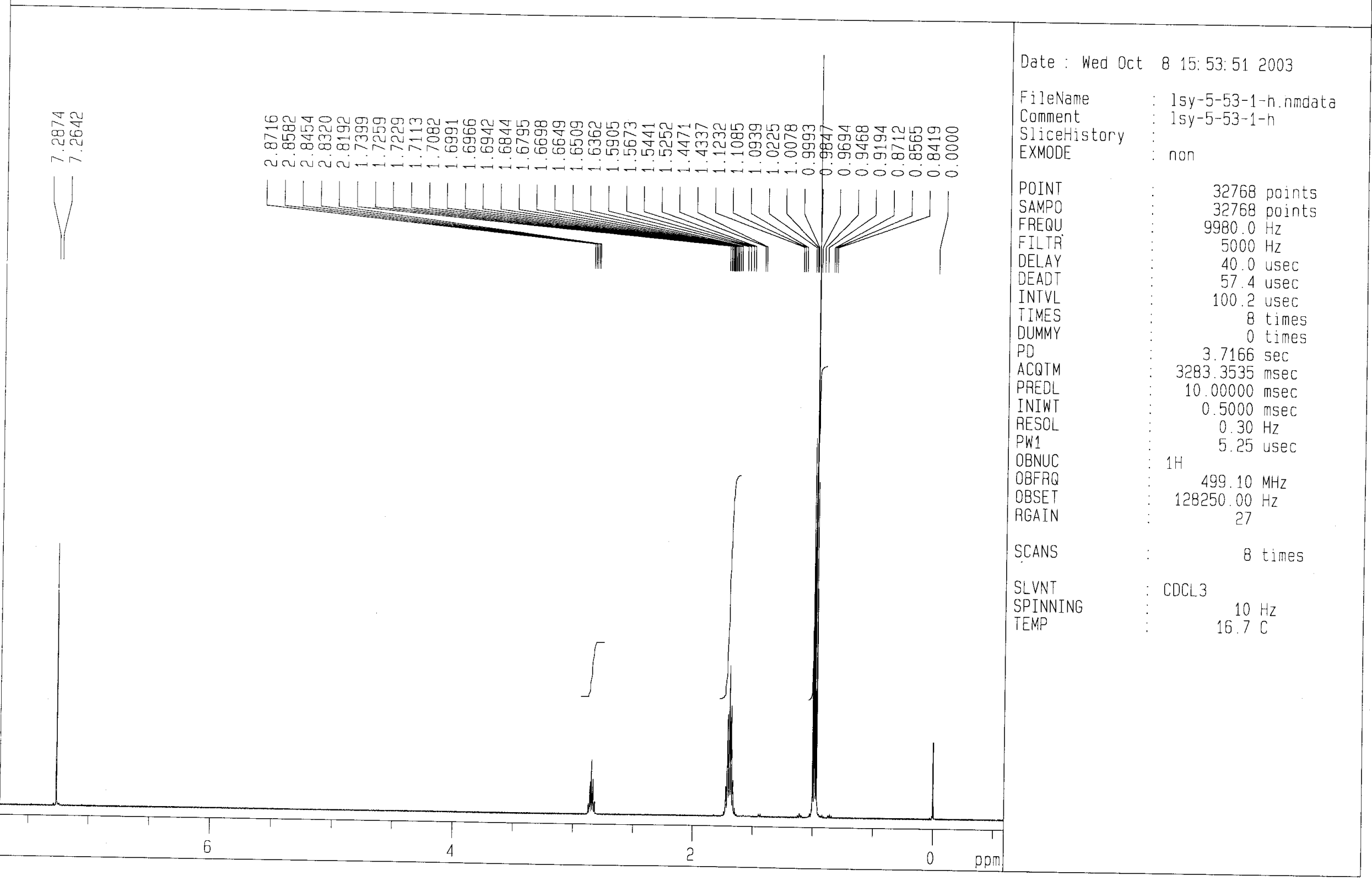


5b $\quad \mathrm{CDCl} 3$ 13C NMR $125 \mathrm{MHz}$

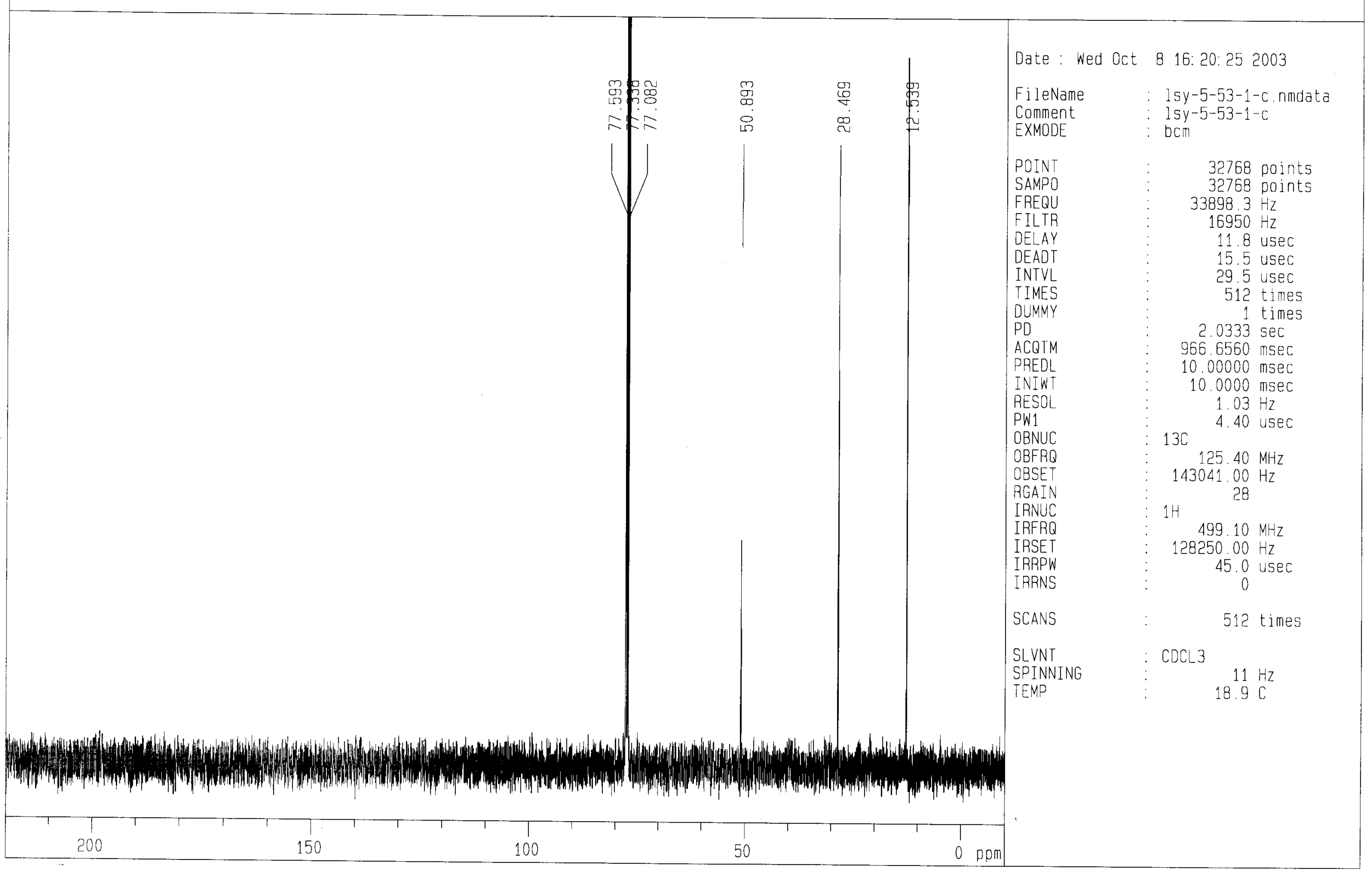




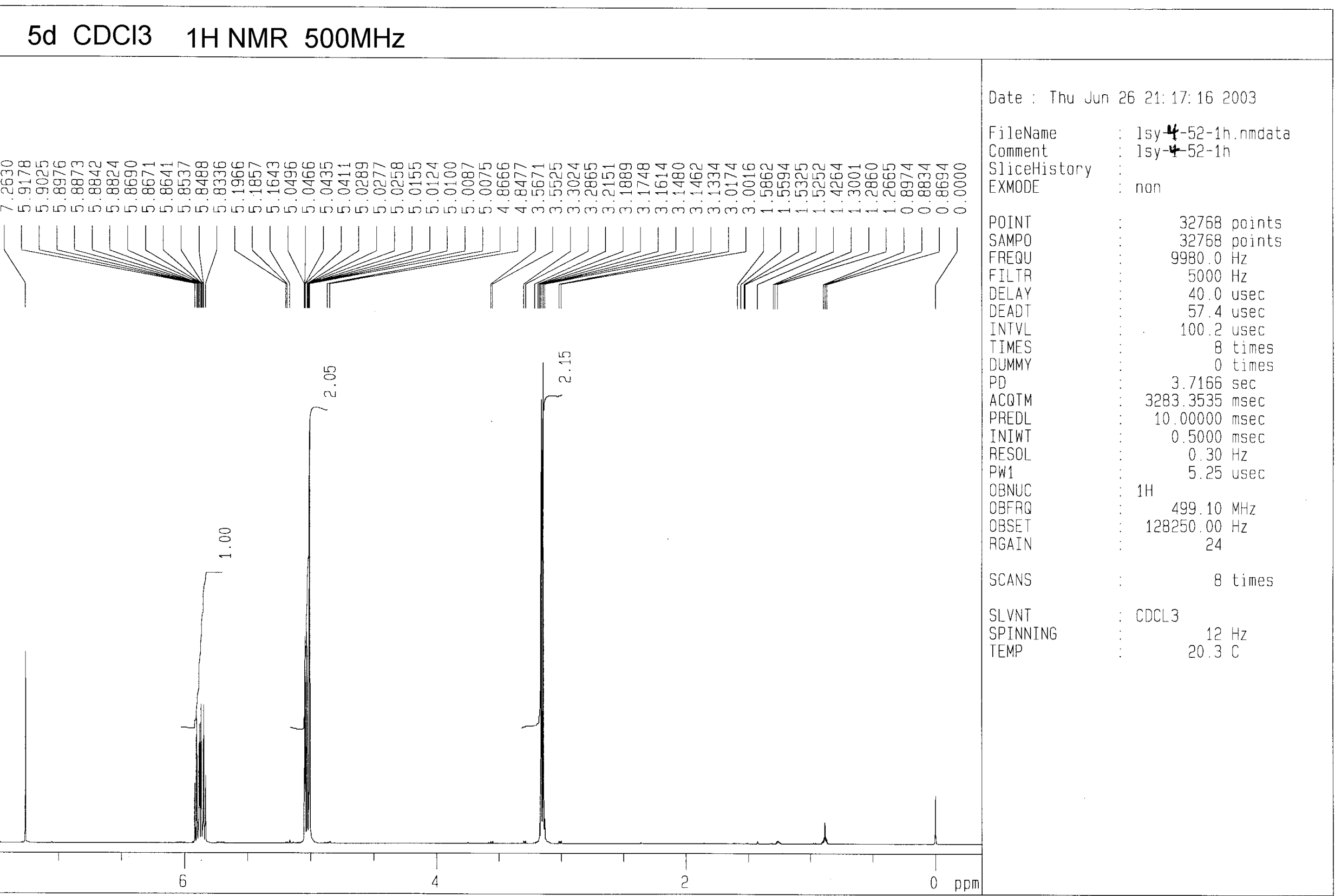


5d CDCl3 13C NMR $125 \mathrm{MHz}$

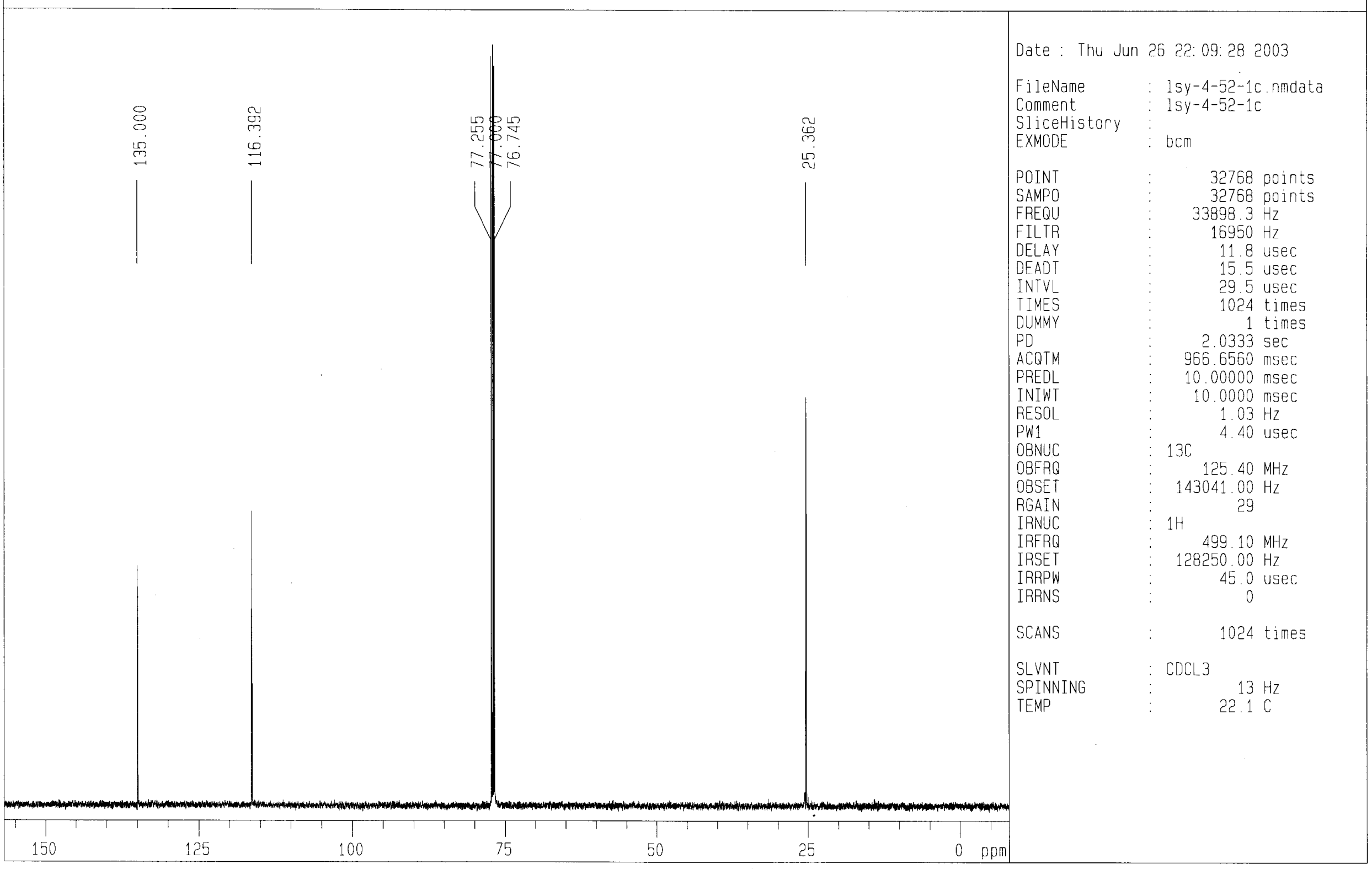




\section{5e $\mathrm{CDCl} 3$ 1H NMR $500 \mathrm{MHz}$}




5e $\mathrm{CDCl} 3$ 13C NMR $125 \mathrm{MHz}$

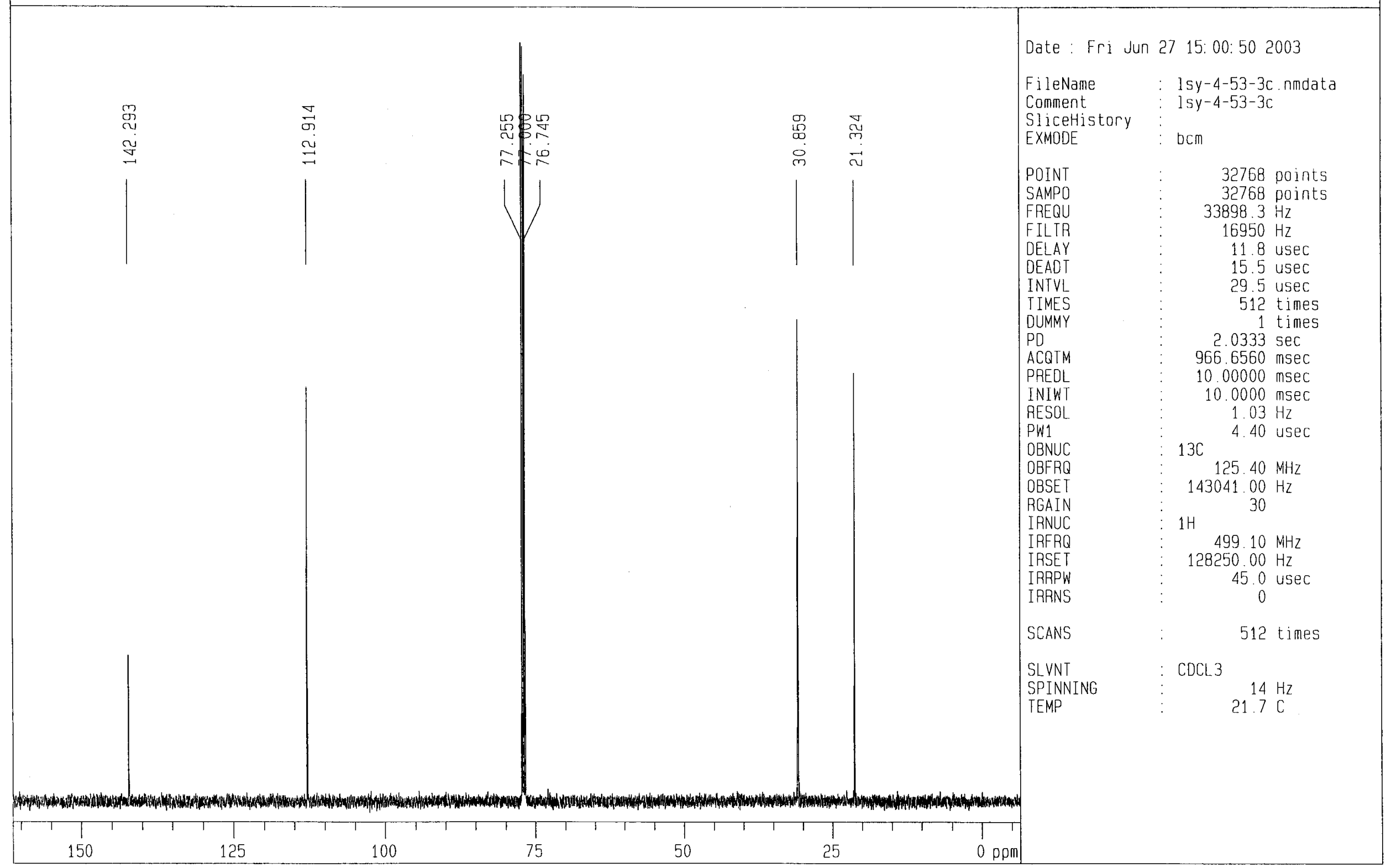

\section{S35}







8e $\mathrm{CDCl} 3$ 13C NMR $125 \mathrm{MHz}$

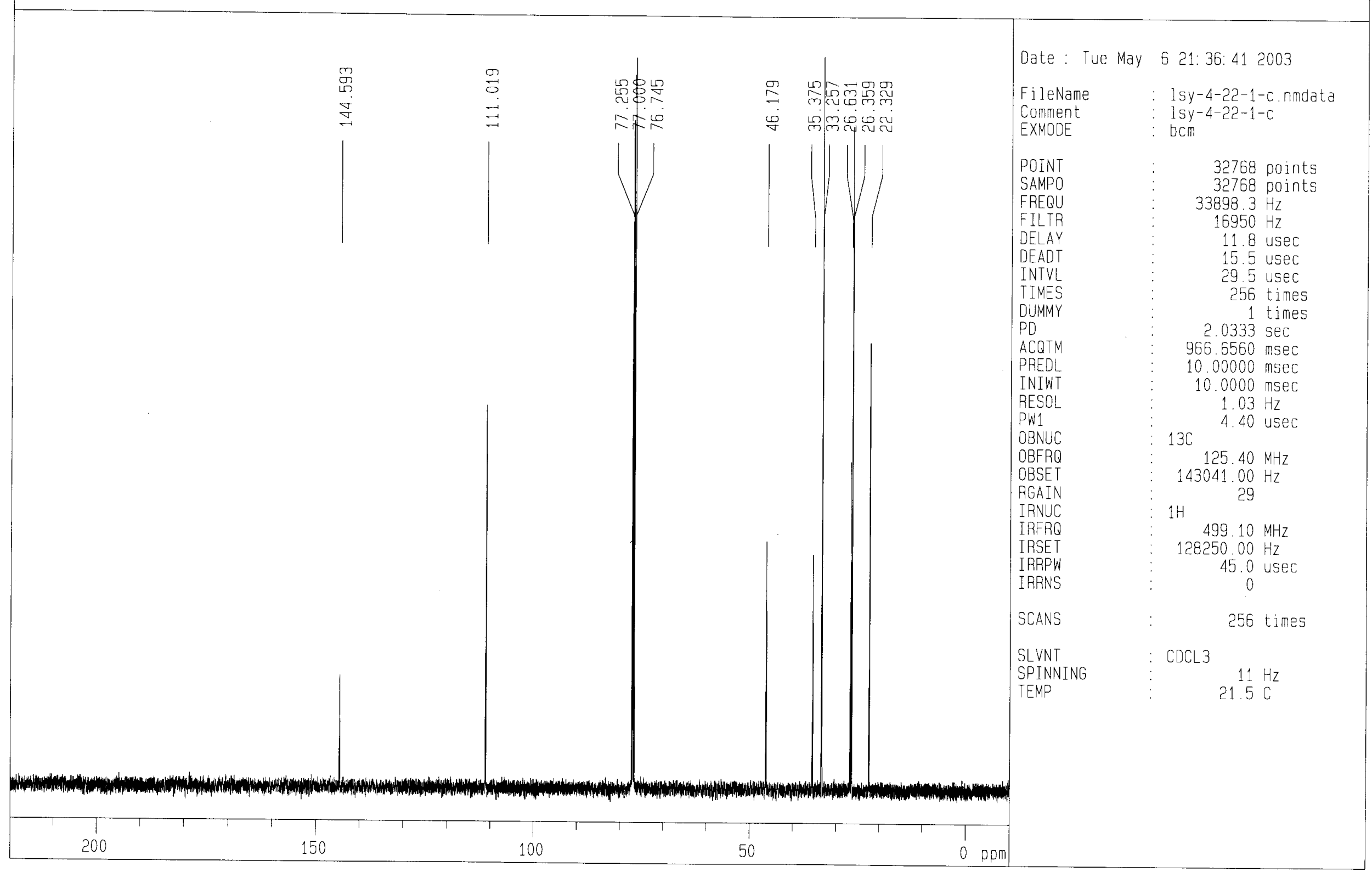

